\title{
Cement Pastes and Mortars Containing Nitrogen-Doped and Oxygen-Functionalized Multiwalled Carbon Nanotubes
}

\author{
Mauricio Martínez-Alanis and Florentino López-Urías \\ Advanced Materials Department, Instituto Potosino de Investigación Científica y Tecnológica, Camino a la Presa San José 2055, \\ Colonia Lomas $4^{a}$ Sección, 78216 San Luis Potosí, SLP, Mexico \\ Correspondence should be addressed to Florentino López-Urías; flo@ipicyt.edu.mx
}

Received 14 September 2015; Revised 23 January 2016; Accepted 27 January 2016

Academic Editor: Hugh J. Byrne

Copyright (C) 2016 M. Martínez-Alanis and F. López-Urías. This is an open access article distributed under the Creative Commons Attribution License, which permits unrestricted use, distribution, and reproduction in any medium, provided the original work is properly cited.

\begin{abstract}
Cement pastes and mortars based on ordinary Portland cement containing nitrogen-doped multiwalled carbon nanotubes $\left(\right.$ MWCNT-N ${ }_{x}$ ) or oxygen-functionalized multiwalled carbon nanotubes $\left(\right.$ MWCNT-O $_{x}$ ) are investigated. To incorporate MWCNTs into the cementitious matrix, the as-produced carpets are dispersed over periods of 1 and 2 hours in distilled water at pH levels of 1 and 7. The cement pastes are prepared by adding $0.1 \mathrm{wt} \%$ of MWCNTs to cement powder, followed by characterization with SEM and $\mathrm{X}$-ray diffraction (XRD) at an early age (first hours of hydration). The mortars are mechanically characterized during the hydration process for a period of 28 days. SEM characterization of cement pastes revealed that the carbon nanotubes are well incorporated in the cementitious matrix, with the hydrated cement grains interconnected by long carbon nanotubes. XRD characterizations demonstrated that, during the hydration of cement pastes, different peaks emerged that were associated with ettringite, hydrated calcium silicate, and calcium hydroxide, among other structures. Results of the compressive strength measurements for mortars simultaneously mixed with MWCNT- $\mathrm{N}_{x}$ and $\mathrm{MWCNT}-\mathrm{O}_{x}$ reached an increment of approximately $30 \%$ in compressive strength. In addition, density functional theory calculations were performed in nitrogen-doped and oxygen-functionalized carbon nanotubes interacting with a cement grain.
\end{abstract}

\section{Introduction}

The potential ability of carbon nanotubes (CNTs) to improve the mechanical properties of hydraulic concrete opens a novel route for the generation of new building materials [110]. Hydraulic concretes are able to adopt any shape due to their aqueous consistency before hardening. Once hardened, hydraulic concretes exhibit high compressive strain. Nevertheless, the concrete that is currently used is a heavy material exhibiting an average mass density of 2.3 tons $/ \mathrm{m}^{3}$ with a time of hardness of approximately 28 days. Currently, the improvement of concrete materials presents several challenges, such as (a) an increase of the mechanical properties (not only compression resistance but also tension resistance and higher elasticity modulus), (b) a reduction of the volumetric mass density, and (c) a reduction of the hydration time. Several works have been performed to improve the properties of currently used concrete, such as the incorporation of fibrous materials [11], steel fibers [12], plastic fibers [13], fly ash from thermal power plants [14], entrapped air [15], recycled tire rubber [16], and recycled concrete [17]. More recently, different nanostructures (nanoparticles, carbon nanotubes, among others) have been incorporated into concrete, demonstrating the possibility of improving its mechanical properties [1822]. The present study considers mixtures of nitrogen-doped or oxygen-functionalized carbon nanotubes with ordinary Portland cement and investigates the texture changes and mechanical properties of cement pastes during the hydration process.

The possible transference of the exceptional mechanical properties of carbon nanotubes [23] to concretes has given rise to several experimental studies on composites of carbon nanotubes and cement [24-32]. For example, Li et al. [24, 25] reported MWCNTs treated with sulfuric acid and a nitric acid mixture solution followed by the addition of modified MWCNTs to cement powder. The authors analyzed the mechanical 
properties, showing that the treated carbon nanotubes can improve the flexural strength, compressive strength, and failure strain of cement matrix composites. They found that there are interfacial interactions between carbon nanotubes and the hydration (such as calcium silicate hydrate (C-S$\mathrm{H}$ ) and calcium hydroxide) of cement. Regarding the role of the dispersion of carbon nanotubes, Konsta-Gdoutos et al. [26] reported an effective dispersion of different lengths of MWCNTs in water by applying ultrasonic energy in combination with the use of a surfactant. Their results suggest that the cement pastes enriched with MWCNTs improve the mechanical properties. Furthermore, Makar and Chan [27] reported that single-walled carbon nanotube (SWCNT) bundles distributed by sonication in isopropanol on OPC grains accelerated the hydration of the OPC compared to both the OPC control samples sonicated alone and the as-delivered OPC. The morphology and location of the tricalcium aluminate ( $\mathrm{C} 3 \mathrm{~A}$ : $\mathrm{Ca}_{3} \mathrm{Al}_{2} \mathrm{O}_{4}$ : celite) hydration products were altered by the presence of the SWCNTs, but no evidence was observed for the nucleation of the $\mathrm{C} 3 \mathrm{~A}$ hydration products on the SWCNT bundles. Tricalcium silicate (C3S: $\mathrm{Ca}_{3} \mathrm{SiO}_{5}$ : alite) hydration reactions were instead responsible for the observed change in the hydration behavior. Both the initial C3S hydration peak at the end of the induction period and the bulk C3S hydration peak were increased in magnitude. However, currently, the separation of carbon nanotubes from bundles represents a crucial problem in the preparation of composite materials based on carbon nanotubes.

Alternatively, Cwirzen et al. [28] reported the effects of surface decoration on the wettability of MWCNTs and the mechanical properties of the cement paste incorporating these dispersions. Their results showed that stable and homogenous dispersions of MWCNTs in water can be obtained by using surface functionalization combined with decoration with polyacrylic acid polymers. The cement paste specimens incorporating these dispersions revealed good workability and a compressive strength increase of approximately $50 \%$, even with only a small addition of MWCNTs ( $0.045-0.15 \%$ of the cement weight). They claimed that there were chemical bonds between the $\mathrm{OH}$ groups of the functionalized MWCNTs and probably the C-S-H phase of the cement matrix. Collins et al. [29] investigated the dispersion, workability, and strength of aqueous MWCNTs and OPC paste mixtures, with and without several generically different dispersants/surfactants that are compatible as admixtures in the manufacture of concrete. These admixtures include an air entrained, styrene butadiene rubber; polycarboxylates; calcium naphthalene sulfonate; and lignosulfonate formulations. Aqueous mixtures were initially assessed for the dispersion of CNTs, followed by workability testing of the selected OPC-CNT-dispersant/surfactant paste mixtures. Abu AlRub et al. [30, 31] investigated the effect of different concentrations of long MWCNTs with high length/diameter aspect ratios of 1250 to 3750 and short MWCNTs with an aspect ratio of approximately 157 in cement paste. Flexural bending tests were performed to evaluate the four major mechanical properties of the cement/CNTs composites at ages of 7 to 28 days. Their results showed that the flexural strength of a short $0.2 \mathrm{wt} \%$ MWCNT and a long $0.1 \mathrm{wt} \%$ MWCNT increased by
$269 \%$ and $65 \%$, respectively, compared to the plain cement sample at 28 days. In another work, Chaipanich et al. [32] reported higher compressive strengths of pastes and mortars based on carbon nanotubes and fly ash cement systems. They found that, for $20 \%$ fly ash cement mortars with $1 \%$ by weight carbon nanotubes, the compressive strength at 28 days was $51.8 \mathrm{MPa}$.

The present study addresses the incorporation of nitrogendoped or oxygen-functionalized multiwalled carbon nanotubes in mortars. To the best of our knowledge, investigations on $\mathrm{N}$-doping nanotubes mixed with mortars have not been reported. Doping carbon nanotubes with nitrogen and other chemical elements induces charge redistribution along the defective area, thus enhancing diverse electronic features and improving the surface reactivity [33, 34], which makes them excellent candidates for diverse applications, such as sensors and composite materials. In Figure 1(a), we schematically show how the nitrogen is set within carbon nanotube lattices via substitution or in pyridine fashion, whereas Figure 1(b) depicts an oxygen-functionalized carbon nanotube exhibiting hydroxyl $(\mathrm{OH})$, carbonyl $(\mathrm{CO})$, or epoxy groups anchored onto its surface [35].

In this work, nitrogen-doped multiwalled carbon nanotubes $\left(\right.$ MWCNTs- $\mathrm{N}_{x}$ ) and oxygen-functionalized multiwalled carbon nanotubes (MWCNTs- $\mathrm{O}_{x}$ ) are used as reinforcements in ordinary Portland cement paste and mortars. The synthesized MWCNT- $\mathrm{N}_{x}$ and $\mathrm{MWCNT}-\mathrm{O}_{x}$ are characterized using scanning electron microscopy and high resolution transmission electron microscopy. The resulting mortars, made from a mixture of nanotubes, cement powder, sand, and water, are characterized using scanning electron microscopy, and compressive strength measurements are performed during the hydration process (from hours to days). Note that, in our approach, no acid treatment is used on the carbon nanotubes. In addition, a possible anchoring mechanism of calcium silicate aggregates on carbon nanotubes is discussed.

\section{Materials and Methods}

2.1. Synthesis of Multiwalled Carbon Nanotubes. MWCNT$\mathrm{N}_{x}$ are synthesized using a chemical vapor deposition (CVD) process; the technique was described by Terrones et al. [33-35]. In our synthesis of carbon nanotubes doped with nitrogen, we used a solution of $94 \mathrm{wt} \%$ benzylamine as the nitrogen and carbon source (dopant) and $6 \mathrm{wt} \%$ ferrocene as the catalyst and carbon source. The mixture was prepared in an amber glass bottle and then dispersed using an ultrasonic bath for 1 hour; next, using a pulverization chamber, the solution was sonicated for a few minutes until it appears as a dense cloud. The cloud was carried through a quartz pipe by the argon gas flow at $2.5 \mathrm{lb} / \mathrm{s}$. The quartz pipe was placed into a muffle at $850^{\circ} \mathrm{C}$, where the carbon nanotubes grew in the inner pipe walls. To synthesize MWCNT-O ${ }_{x}$, a similar process was followed, using a combination of toluene and ethanol as the carbon and oxygen sources and ferrocene as the catalyst. This synthesis was performed over 30 minutes. All of the chemical substances were acquired from Sigma-Aldrich Company. 

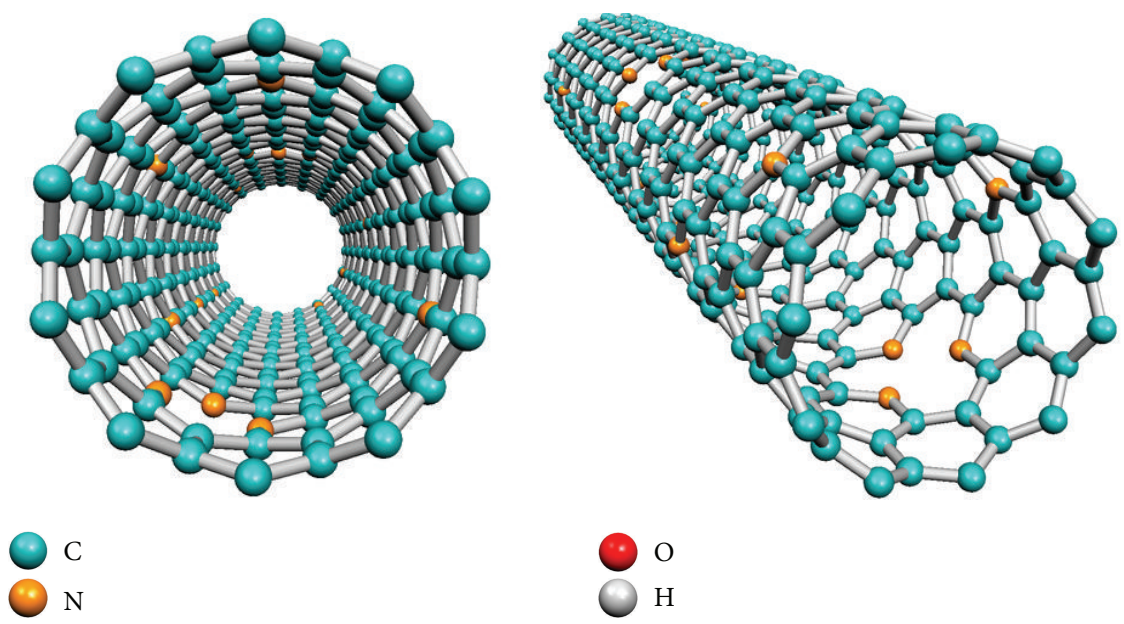

(a) Nitrogen-doped single-walled carbon nanotube (SWCNT-N)
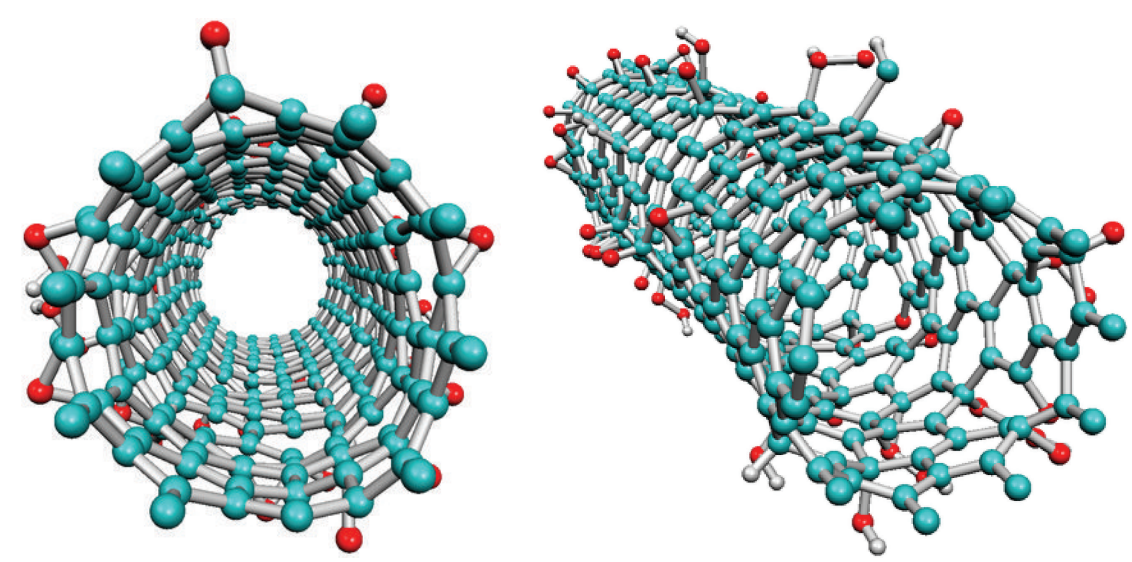

$\odot \mathrm{C}$

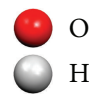

(b) Oxygen-functionalized single-walled carbon nanotube ( SWCNT-O $\left._{x}\right)$

FIGURE 1: Ball-stick models showing the following. (a) Nitrogen-doped single-walled carbon nanotubes (SWCNT-N S $_{x}$; here, nitrogensubstitutional and nitrogen-pyridine sites are substituted into the lattice of the carbon nanotubes. (b) Oxygen-functionalized single-walled carbon nanotubes (SWCNTs- $\left.\mathrm{O}_{x}\right)$ exhibiting O-epoxy, carbonyl $(\mathrm{C}=\mathrm{O})$, and hydroxyl $(-\mathrm{OH})$ groups attached on the surface of the carbon nanotube.

2.2. Cement Paste and Concrete Preparation. The process used to prepare cement pastes mixtures according to the common practice in laboratory construction materials consisted of blending $74.6 \mathrm{~g}$ of ordinary Portland gray cement (purchased from a local material cement house Moctezuma cpc $30 \mathrm{R}$, and the chemical composition and grain morphologies of which are shown in Figure 2), $248.23 \mathrm{~g}$ of natural sand with a grain size in the range from 0.2 to $0.5 \mathrm{~mm}, 59.6$ milliliters of water, and 74.61 milligrams of carbon nanotubes (quantities per specimen). Therefore, the water/cement and the sand/cement were 0.798 and 3.32, respectively. The sand was introduced in a rotary mixer for one minute; subsequently, cement was added and rotated over 2 minutes. Next, a solution based on water and carbon nanotubes was added using three rotation cycles of 5 minutes each. When a cycle was terminated, the mixture was left to stand for 3 minutes. Thereafter, the mixed concrete was poured into molds to form cylindrical samples with a height of $10 \mathrm{~cm}$ and a diameter of $5 \mathrm{~cm}$; subsequently, these cylindrical samples (specimens test) were subjected to compression tests. Table 1 shows the number of specimens that were tested by considering different water $\mathrm{pH}$ levels and sonication times. Therefore, a total of 180 specimens were fabricated, plus the specimens corresponding to mortars without carbon nanotubes (control group).

The resulting mortars were tested during their hydration at 3,14 , and 28 days. The $\mathrm{pH}$ of the water added to the cement and nanotube mixture was adjusted using hypochlorous acid $(\mathrm{HClO})$ and measured with an electronic $\mathrm{pH}$-meter. The compression strength test was conducted on a Shimadzu universal press mark with a 5-ton capacity; the parameters were adjusted to the C39C/C39M standard under the American Society for Testing and Materials (ASTM) normative. This test method consisted of applying a compressive axial load 
TABLE 1: Numbers of the specimens used in the compression strength tests. The $\mathrm{pH}$ value, dispersion time of the nanotubes samples, and day of the measurement are indicated.

\begin{tabular}{|c|c|c|c|c|c|c|c|c|c|c|c|c|}
\hline \multirow[b]{2}{*}{ Day of measurement } & \multicolumn{3}{|c|}{$\begin{array}{c}\mathrm{pH}=1 \\
\text { Dispersion time } 1 \mathrm{~h}\end{array}$} & \multicolumn{3}{|c|}{$\begin{array}{c}\mathrm{pH}=1 \\
\text { Dispersion time } 2 \mathrm{~h}\end{array}$} & \multicolumn{3}{|c|}{$\begin{array}{c}\mathrm{pH}=7 \\
\text { Dispersion time } 1 \mathrm{~h}\end{array}$} & \multicolumn{3}{|c|}{$\begin{array}{c}\mathrm{pH}=7 \\
\text { Dispersion time } 2 \mathrm{~h}\end{array}$} \\
\hline & 3 & 14 & 28 & 3 & 14 & 28 & 3 & 14 & 28 & 3 & 14 & 28 \\
\hline MWCNT-N $_{x}$ & 5 & 5 & 5 & 5 & 5 & 5 & 5 & 5 & 5 & 5 & 5 & 5 \\
\hline MWCNT-O $_{x}$ & 5 & 5 & 5 & 5 & 5 & 5 & 5 & 5 & 5 & 5 & 5 & 5 \\
\hline MWCNT- $\left(\mathrm{N}_{x}+\mathrm{O}_{x}\right)$ & 5 & 5 & 5 & 5 & 5 & 5 & 5 & 5 & 5 & 5 & 5 & 5 \\
\hline Total specimens & 15 & 15 & 15 & 15 & 15 & 15 & 15 & 15 & 15 & 15 & 15 & 15 \\
\hline
\end{tabular}

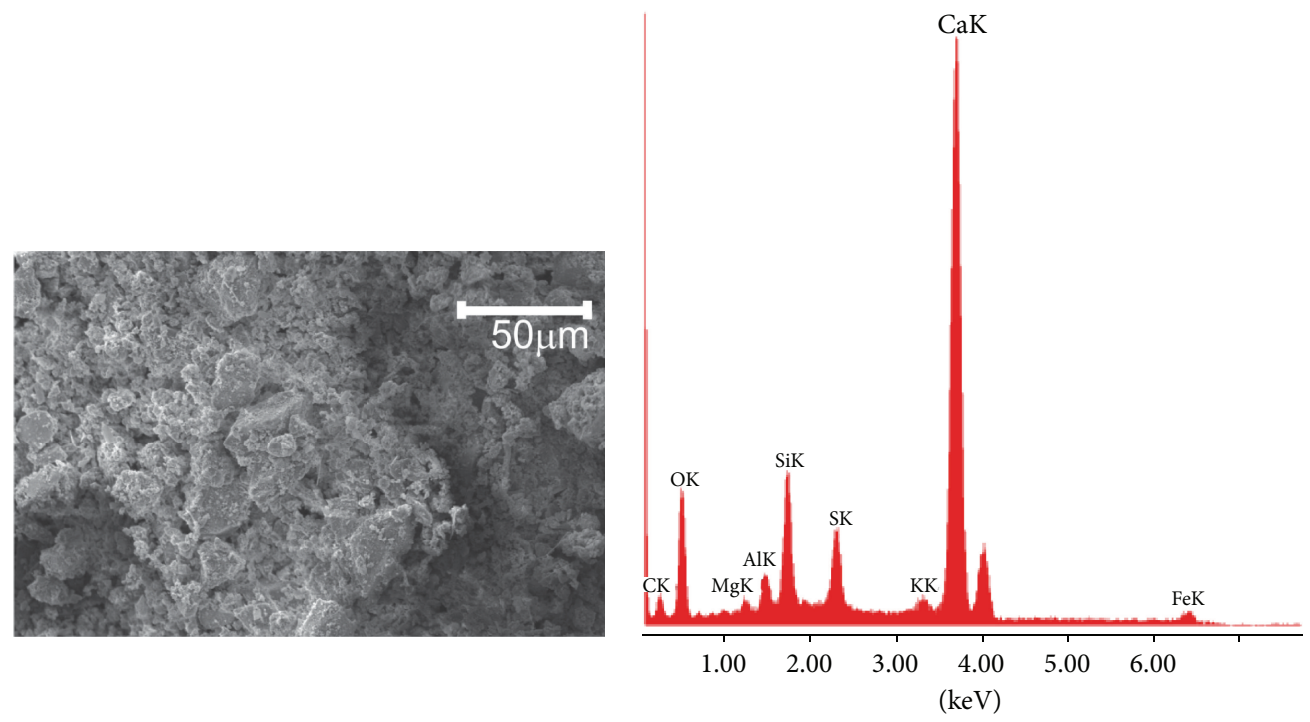

(a)

(b)

\begin{tabular}{lcc}
\hline Element & $\mathrm{wt} \%$ & at\% \\
\hline $\mathrm{CK}$ & 8.3 & 15.59 \\
$\mathrm{OK}$ & 35.43 & 49.96 \\
$\mathrm{MgK}$ & 0.97 & 0.9 \\
$\mathrm{AlK}$ & 2.07 & 1.73 \\
$\mathrm{SiK}$ & 6.47 & 5.2 \\
$\mathrm{SK}$ & 4.19 & 2.95 \\
$\mathrm{KK}$ & 1.15 & 0.66 \\
$\mathrm{CaK}$ & 39.45 & 22.21 \\
$\mathrm{FeK}$ & 1.97 & 0.8 \\
\hline
\end{tabular}

(c)

FIGURE 2: (a) SEM image of the ordinary Portland cement (OPC) powder and (b)-(c) the corresponding chemical composition determined via energy-dispersive X-ray spectroscopy (EDX).

to molded cylinders at a rate that was within the prescribed range until failure occurred; the compressive strength of the specimen was calculated by dividing the maximum load attained during the test according to the cross-sectional area of the specimen. The axial load was applied in all cases continuously and without shock at a rate of $1 \mathrm{~mm} / \mathrm{min}$.

\section{Computational Details}

Simulations of carbon nanotubes interacting with calcium silicates aggregates were performed using density functional theory [36, 37]. The generalized gradient approximation (GGA) with the PBE parametrization was chosen for the exchange-correlation functional [38], as implemented in the SIESTA code [39]. The wave functions for the valence electrons were represented by a linear combination of pseudoatomic numerical orbitals using a simple- $z$ basis (S $\xi$ ) [40], while the core electrons were represented by norm-conserving Troullier-Martins pseudopotentials in the Kleinman-Bylander nonlocal form [41, 42]. The real-space grid used for charge and potential integration was equivalent to a plane wave cut-off energy of $150 \mathrm{Ry}$. The pseudopotentials (PPs) were 


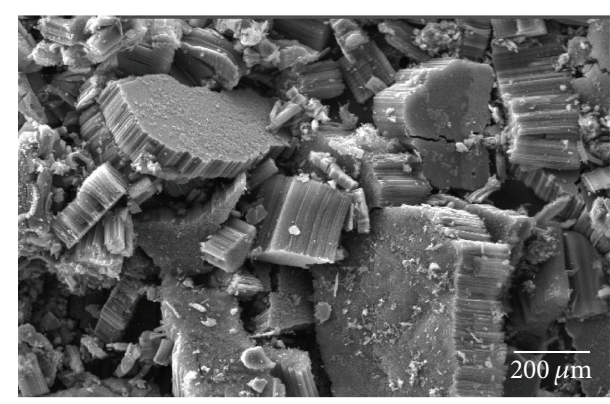

(a) $\operatorname{MWCNT}-\mathrm{O}_{x}$

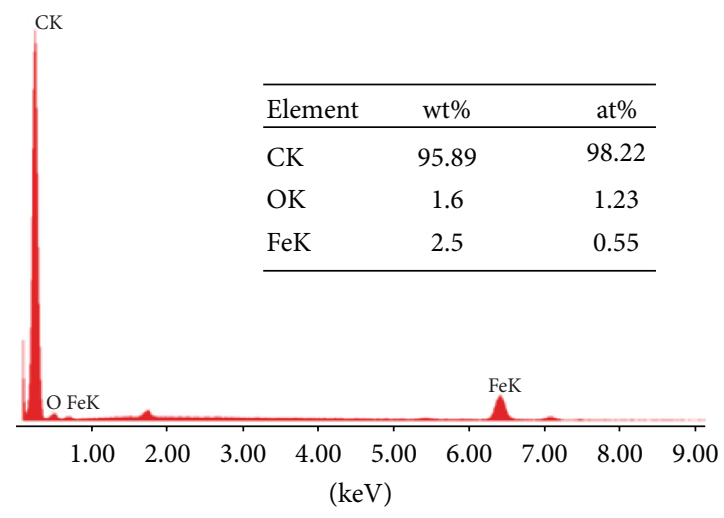

(c)

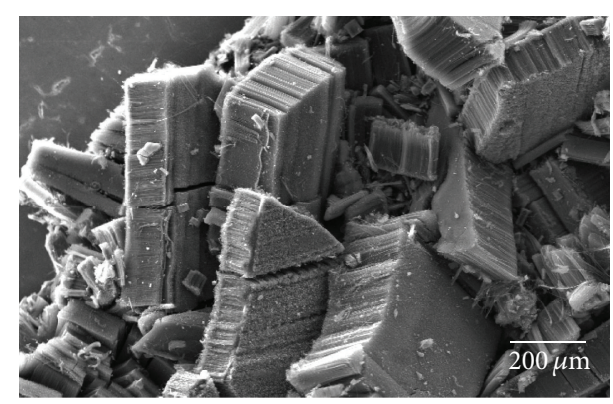

(b) MWCNT-N $_{x}$

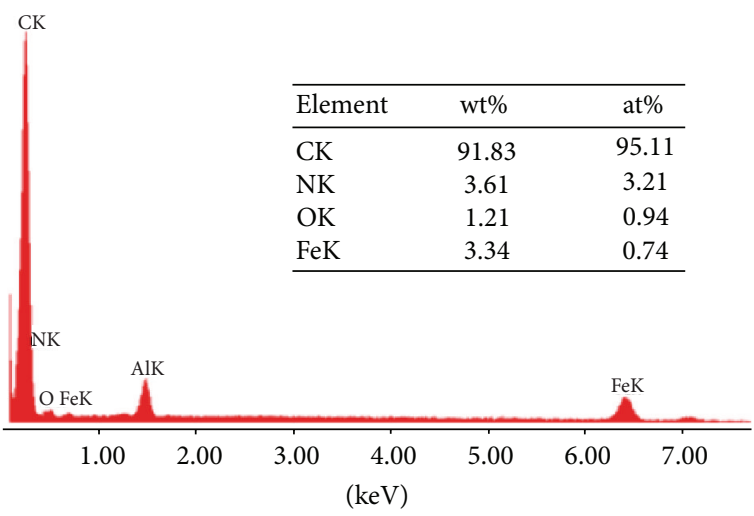

(d)

FIGURE 3: SEM images and EDX characterization of the as-produced carbon nanotubes; (a) and (c) correspond to the MWCNT-O $_{x}$ sample; (b) and (d) correspond to the MWCNT- $\mathrm{N}_{x}$ sample. The samples show bundles formed by aligned carbon nanotubes, the lengths of carbon nanotubes are in the range of 100 to $300 \mu \mathrm{m}$, and the diameters range from 30 to $70 \mathrm{~nm}$.

constructed from the corresponding valence electrons for each element ( $\mathrm{H}: 1 \mathrm{~s}^{1}, \mathrm{C}: 2 \mathrm{~s}^{2} 2 \mathrm{p}^{2}, \mathrm{~N}: 2 \mathrm{~s}^{2} 2 \mathrm{p}^{3}, \mathrm{O}: 2 \mathrm{~s}^{2} 2 \mathrm{p}^{4}, \mathrm{Si}$ : $3 s^{2} 3 p^{2}$, and Ca: $\left.3 s^{2} 3 p^{4}\right)$. Periodic boundary conditions were used, and the internanotube distance was kept to a minimum of $\sim 40 \AA$ to avoid lateral interactions. All of the systems were relaxed by conjugate gradient minimization until the maximum force was less than $0.04 \mathrm{eV} / \AA$.

\section{Results and Discussions}

4.1. Carbon Nanotubes Production and Characterization. Figure 3 depicts scanning electron microscopy (SEM) images and energy-dispersive X-ray spectroscopy (EDX) analysis of as-produced nanotubes exhibiting densely packed nanotube arrays (bundles) of different sizes $(200-500 \mu \mathrm{m})$. The samples consisted of aligned MWCNT- $\mathrm{N}_{x}$ and oxygen-functionalized carbon nanotubes (MWCNTs- $\mathrm{O}_{x}$ ), which were produced at $850^{\circ} \mathrm{C}$ using a chemical vapor deposition method. In general, MWCNT-O ${ }_{x}$ exhibited larger lengths than MWCNT-N M $_{x}$. The produced carbon nanotube bundles were sonicated using an ultrasonic processor with the following specifications: power $=1500$ Watts and frequency $=20 \mathrm{kHz}$; the experimental setup is shown in Figures 4(a)-4(c). To separate carbon nanotubes from the bundles, the samples were sonicated for 1 or 2 hours in water; the sonicated samples exhibited good dispersion, with minor damage to the walls of the carbon nanotubes. TEM images show well-dispersed samples of large carbon nanotubes; see Figures 4(d)-4(f). The asproduced $\mathrm{N}$-doped carbon or oxidized carbon nanotubes present active sites in the surface; in contrast, for undoped or pristine carbon nanotubes, defects or surface damage is required to create active sites in their surface. These active sites are important to ensure good interactions between the carbon nanotubes and cement matrix. An interesting investigation on the effect of the ultrasonication in carbon nanotubes was reported by Chen et al. [43]; they found that intense ultrasonication may damage the sidewalls of carbon nanotubes and create surface defects that influence the interaction between carbon nanotubes and the cementitious matrix. Figure 5 displays transmission electron microscopy (TEM) images of a dispersed sample containing MWCNT- $\mathrm{N}_{x}$ and MWCNT-O $\mathrm{O}_{x}$. Figures 5(a) and 5(b) show MWCNT-N $\mathrm{N}_{x}$ that are $20-40 \mathrm{~nm}$ in diameter with the well-known bamboolike morphology [22]. The dark spots inside the MWCNT$\mathrm{N}_{x}$ correspond to $\mathrm{Fe}$ particles, which are responsible for nanotube formation during the chemical vapor deposition process $[22,23]$. Figure 5(c) displays a high resolution TEM (HRTEM) image of a carbon nanotube, where the graphite walls can be observed to have an interlayer distance of $0.34 \mathrm{~nm}$. Experimental evidence on the nitrogen doping in multiwalled carbon nanotubes was previously reported [22]. Figure 5(d) displays a TEM image of a MWCNT-O Mample $_{x}$ showing long nanotubes. It is important to remark that our MWCNT- $\mathrm{O}_{x}$ has grown by using chemical vapor deposition 

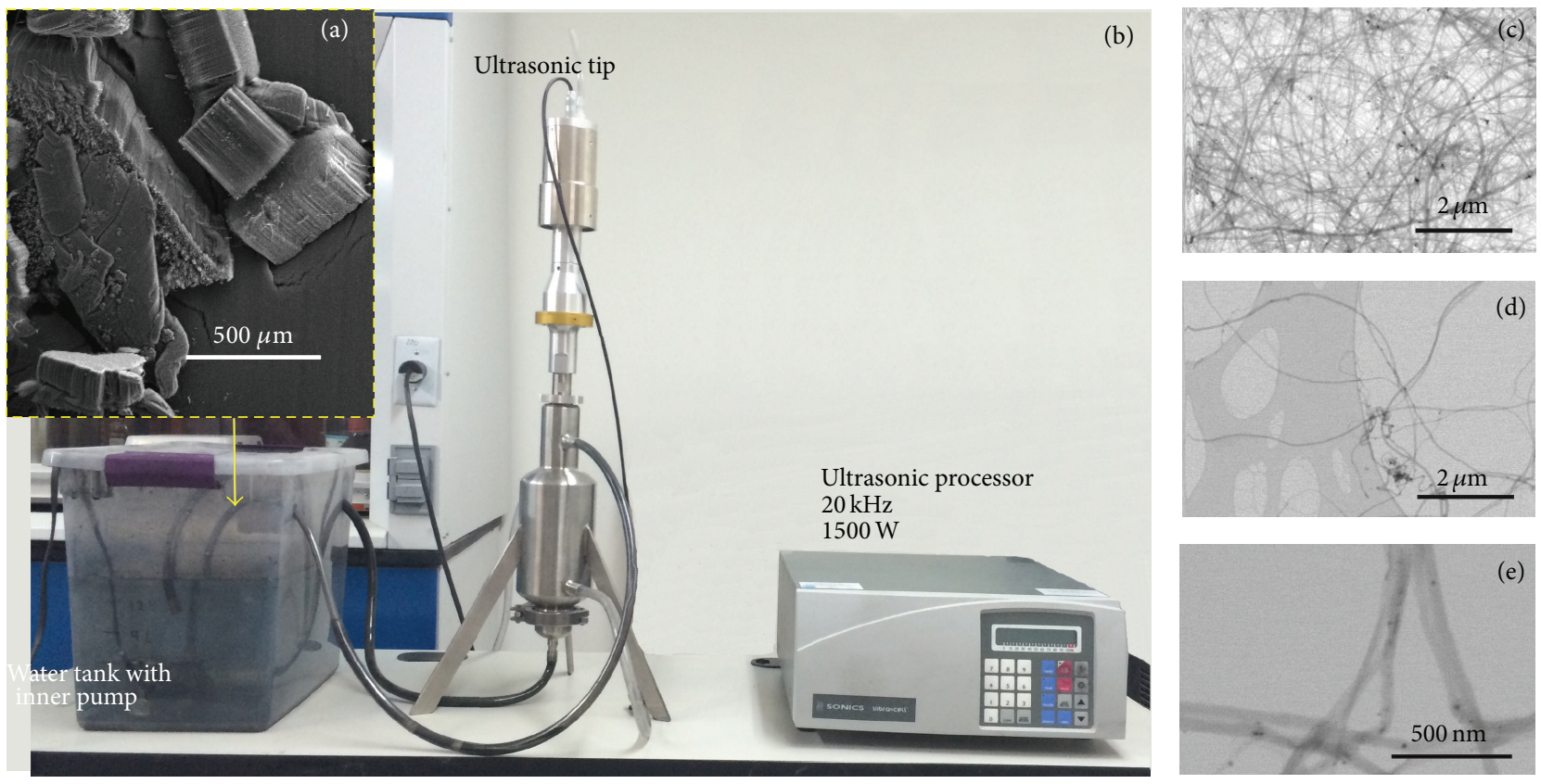

FIGURE 4: Methodology for the dispersion of carbon nanotubes. (a) SEM micrograph showing as-produced carbon nanotubes (bundles), which are introduced in a water tank. A pump is installed inside the water tank to supply the solution based on water + carbon nanotubes to the ultrasonic tip equipment. (b) Ultrasonic tip equipment connected to an ultrasonic processor operated at $20 \mathrm{kHz}$ and $1500 \mathrm{Watts}$. (c), (d), and (e) TEM images showing the resulting dispersed carbon nanotubes.
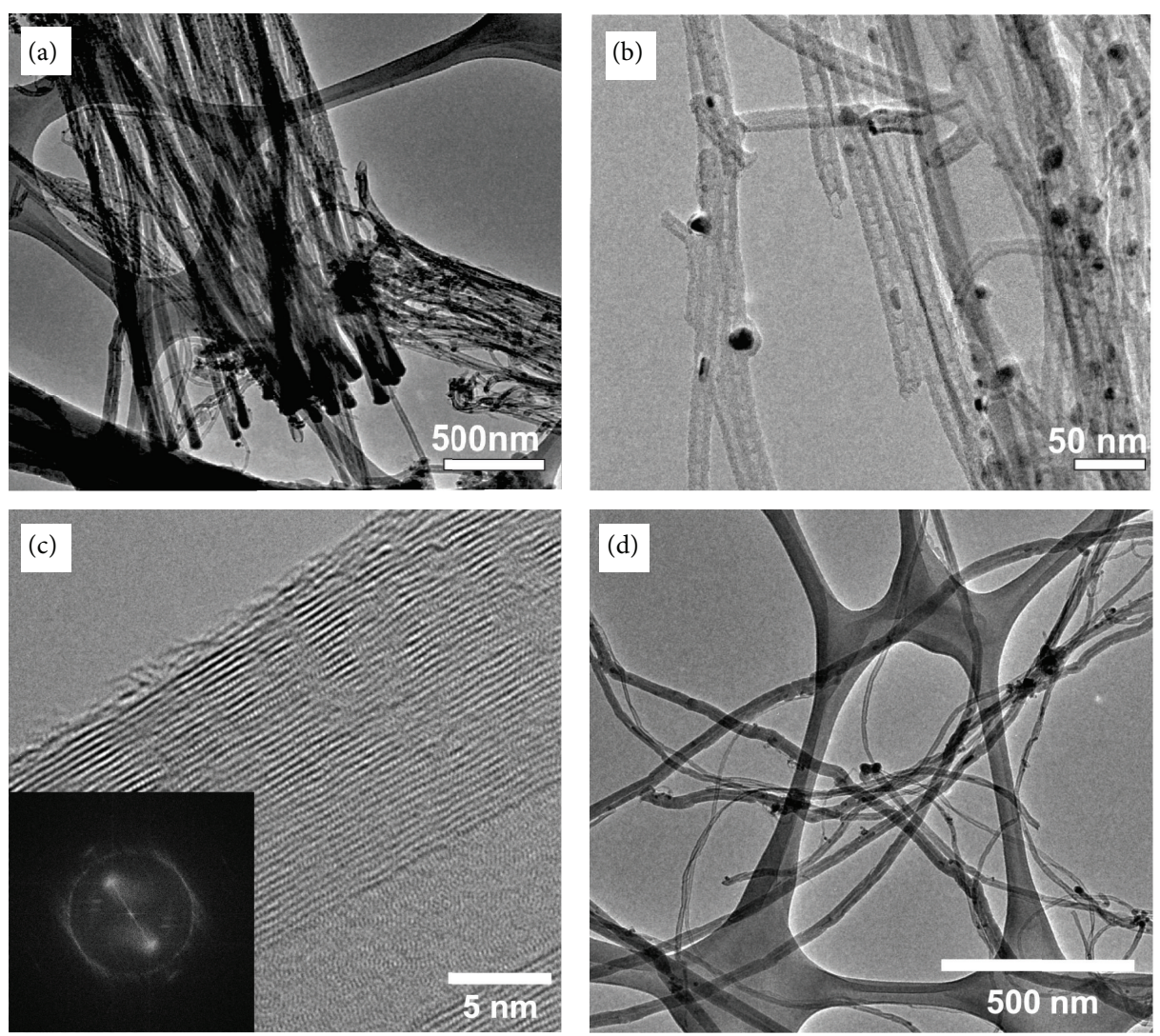

Figure 5: (a) and (b) TEM images of nitrogen-doped multiwalled carbon nanotubes (MWCNTs- $\mathrm{N}_{x}$ ). Dark spots correspond to Fe catalystnanoparticles. (c) High resolution TEM image of MWCNT- $\mathrm{N}_{x}$ showing the well-defined graphitic layers of carbon nanotube walls. (d) TEM image depicting oxygen-functionalized multiwalled carbon nanotubes $\left(\right.$ MWCNTs- $\mathrm{O}_{x}$ ) containing Fe inside. 


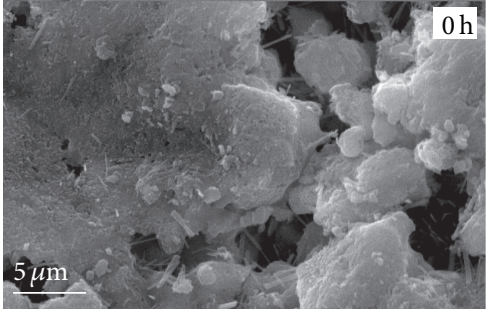

(a) Cement paste without MWCNT

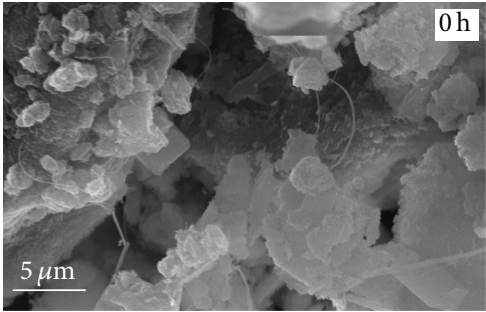

(d) Cement paste with MWCNT-N

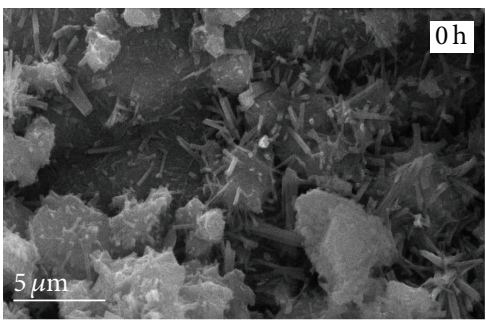

(g) Cement paste with MWCNT-O

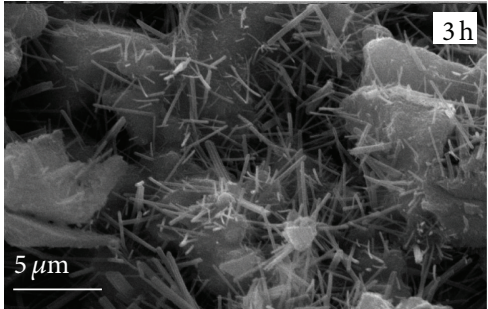

(b) Cement paste without MWCNT

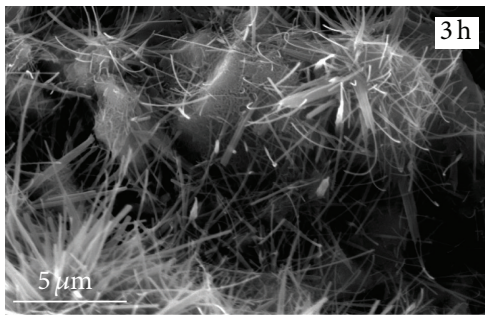

(e) Cement paste with MWCNT-N

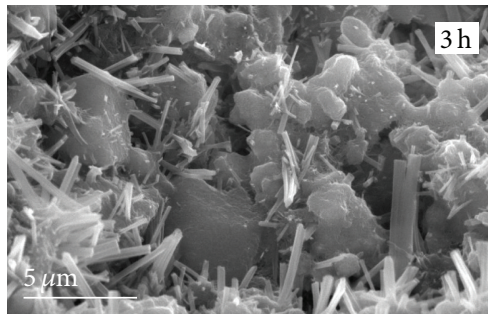

(h) Cement paste with MWCNT-O

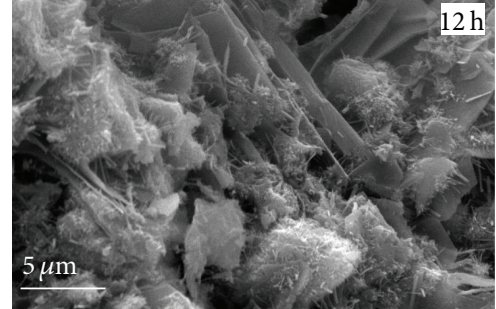

(c) Cement paste without MWCNT

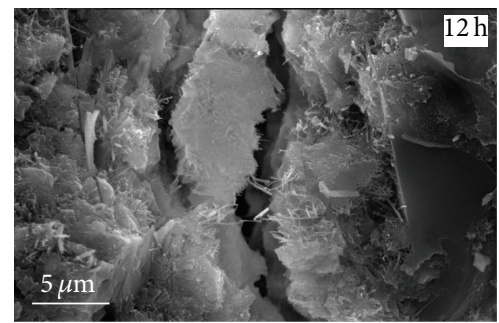

(f) Cement paste with MWCNT-N

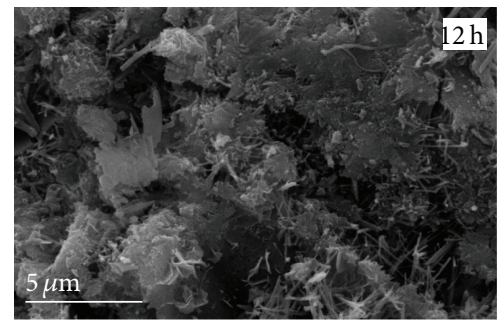

(i) Cement paste with MWCNT-O

Figure 6: SEM images of hydrated Portland cement paste at the initial hours of the hydration process. The images in (a), (b), and (c) represent the cement paste based on ordinary Portland cement (OPC) without carbon nanotubes. The images in (d), (e), and (f) display cement paste based on OPC and nitrogen-doped carbon nanotubes (MWCNTs- $\left.\mathrm{N}_{x}\right)$. The images in $(\mathrm{g})$, (h), and (i) display cement paste

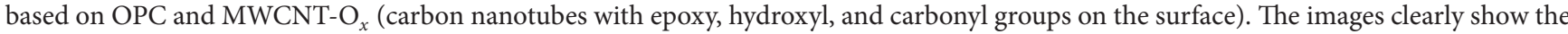
time-dependent morphology of the samples. The MWCNT- $\mathrm{N}_{x}$ concentration in all of the samples is $0.1 \%$ with respect to the cement mass; a similar concentration is also used for samples with MWCNT-O .

using ethanol solvent as oxygen and carbon precursors, and thus during the growth of carbon nanotubes, different oxygen functional groups are attached to the walls of the carbon nanotubes. A detailed analysis of the different oxygen functional groups in $\mathrm{MWCNT}^{-\mathrm{O}_{x}}$ using X-ray photoelectron spectroscopy was investigated by Botello-Méndez et al. [35]. Note that the produced carbon nanotubes (MWCNT-N and $\mathrm{MWCNT}-\mathrm{O}_{x}$ ) present intrinsic active sites that do not require an acid treatment. Also note that an acid treatment could damage the structure of carbon nanotubes, thereby weakening their mechanical properties.

4.2. Characterization of Cement Pastes. The analyzed cement pastes were prepared by mixing ordinary Portland cement (OPC) with MWCNT-N ${ }_{x}$, MWCNT-O $x$, and MWCNT- $\left(\mathrm{N}_{x}\right.$ $+\mathrm{O}_{x}$ ) using different values of the water $\mathrm{pH}$. Figure 6 shows SEM images of the cement paste during the first hours of hydration. The results using only OPC are depicted in Figures 6(a), 6(b), and 6(c) (first row in Figure 6). For cement paste with a hydration time of only a few minutes $(0 \mathrm{~h})$, the SEM image contains large aggregates formed presumably by OPC and a few rod shape structures (see Figure 6(a)). The results for 3 and 12 hours of hydration time are shown in Figures 6(b) and $6(\mathrm{c})$, respectively. Note that the SEM images exhibit large aggregates with morphologies of plates and faceted rods corresponding to calcium hydroxide and ettringite structures, respectively. SEM characterization of the cement paste based on OPC + MWCNT-N $_{x}$ is shown in Figures 6(d), 6(e), and 6 (f) for 0,3 , and 12 hours of hydration, respectively. In the early stages (a few minutes of hydration time), little activity can be observed, with only some carbon nanotubes encrusted in the calcium silicate grains (see Figure 6(d)). Clearly, during hydration of the cement paste, needle-shape structures with small diameters grown on calcium silicate aggregates are formed (see Figure 6(e)). These needle-shaped structures are not observed in other samples. SEM images of cement paste containing $\mathrm{MWCNT}-\mathrm{O}_{x}$ nanotubes are shown in Figures $6(\mathrm{~g}), 6(\mathrm{~h})$, and $6(\mathrm{i})$ for 0,3 , and 12 hours of hydration, respectively. In contrast, cement pastes based on OPC + MWCNT-O ${ }_{x}$ exhibit large ettringite rod-shaped structures, which were already formed after 3 hours of hydration. The oxygen and hydrogen species contribution provided by this 


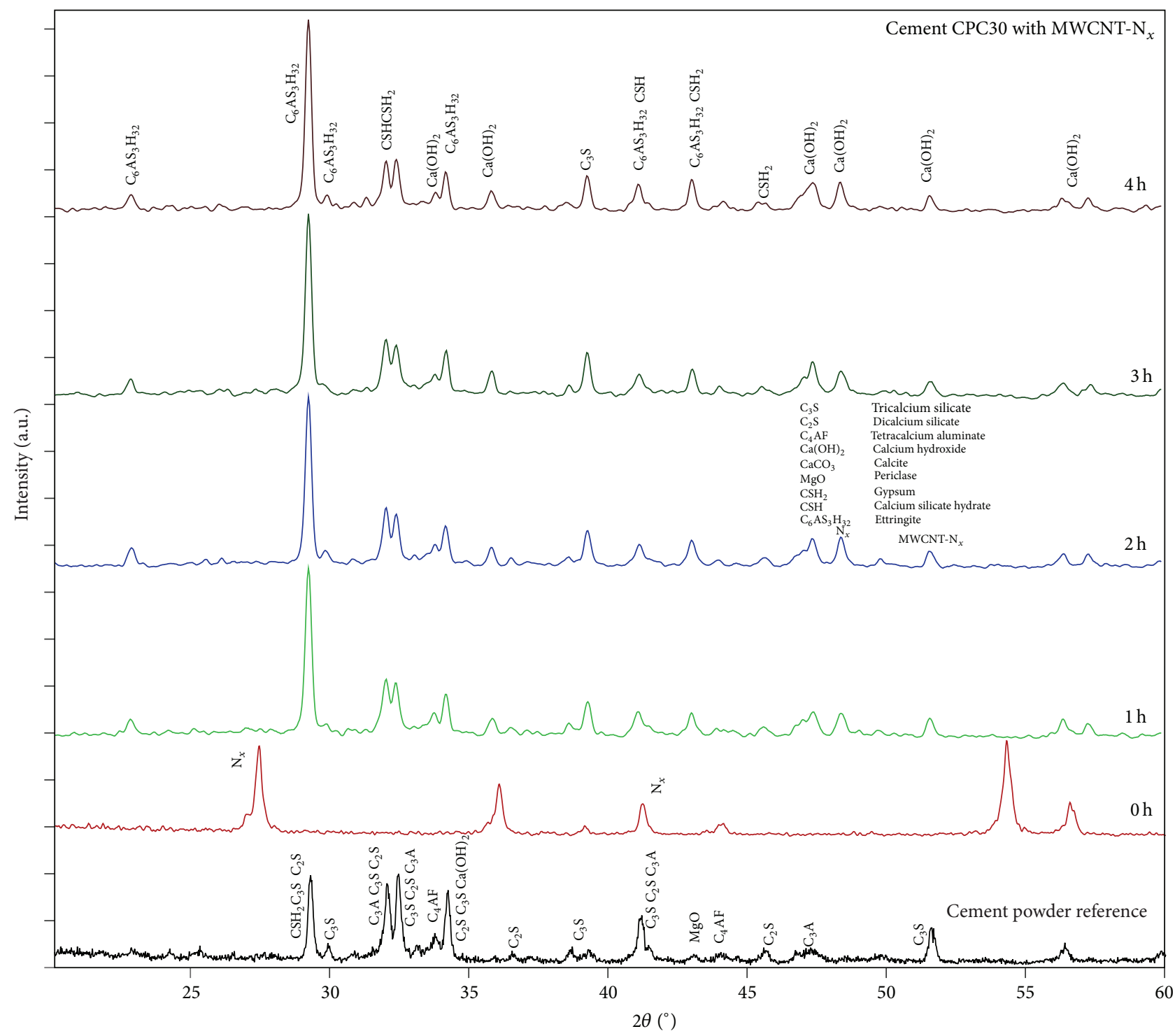

FIGURE 7: X-ray diffraction patterns for cement pastes with MWCNT-N $_{x}$ during the hydration. The pattern for pure cement powder is also shown. After one hour of hydration, the peaks corresponding to the ettringite structure and hydrated calcium silicate emerge in accord with the SEM images. Surprisingly, for zero hours of hydration (few minutes of hydration), several peaks are suppressed; the peak appearing at approximately 27 degrees suggests the presence of carbon nanotubes, and the peak at approximately 55 degrees could be associated with the iron-carbide or $\alpha$-Fe nanoparticles contained inside carbon nanotubes.

type of nanotubes could accelerate the hydration process in the cement paste.

Figure 7 displays the XRD characterization of the cement paste with MWCNT-N ${ }_{x}$ for zero hours of hydration (few minutes of hydration); several peaks are suppressed; a peak appearing at approximately 27 degrees suggests the presence of carbon nanotubes; and additional peaks at approximately 55 degrees indicate the presence of iron-carbide or $\alpha$-Fe nanoparticles contained inside the carbon nanotubes. Furthermore, it is appreciated that, after an hour of hydration, the peaks corresponding to the ettringite structure, hydrated calcium silicate, and calcium hydroxide, among others, are present. The XRD characterization results for the cement paste with MWCNT-O ${ }_{x}$ show similar trends to that obtained for cement paste with MWCNT-N ${ }_{x}$.

Figure 8 displays SEM images of the cement pastes containing MWCNT- $\mathrm{N}_{x}$ nanotubes at different hydration ages. Figures 8(a) and 8(b) show a carbon nanotube forming a bridge between two cement grains. Note that the nanotube is presumably covered by material, and a bar-shaped structure is grown on it. The coverage material and the bar structure could be formed by an ettringite-like structure. Figure 8(c) shows carbon nanotubes embedded in cement grains, and Figure 8 (d) displays a long carbon nanotube stretched by two cement grains. Figures $8(\mathrm{e})$ and $8(\mathrm{~h})$ exhibit cement grains at early age growing on a tangle of nanotubes. In both cases, 


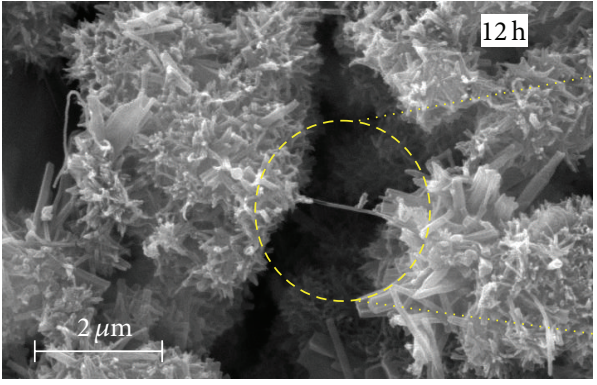

(a) Cement paste with MWCNT-N ${ }_{x}$

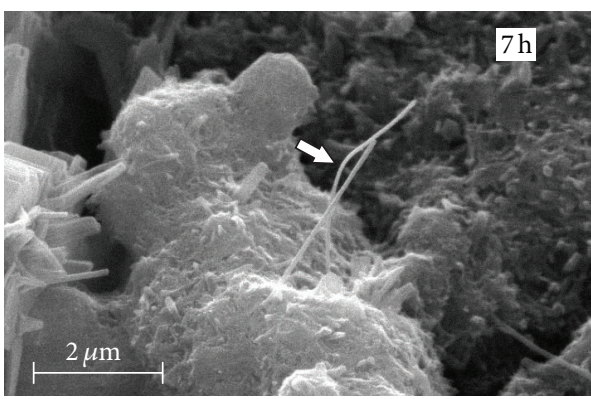

(c) Cement paste with MWCNT-N $x$

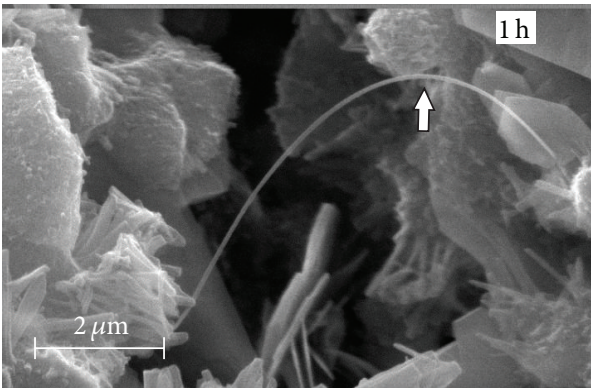

(e) Cement paste with MWCNT-N ${ }_{x}$

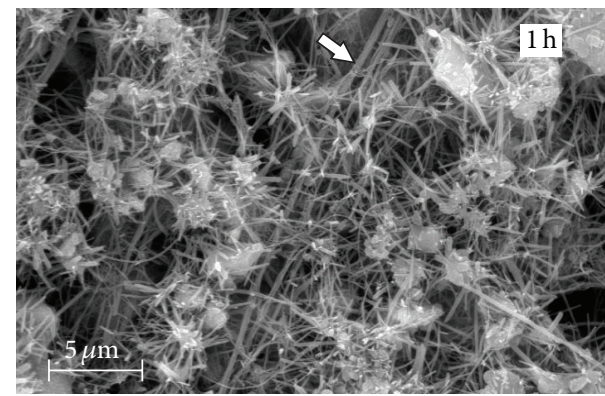

(g) Cement paste with MWCNT-N

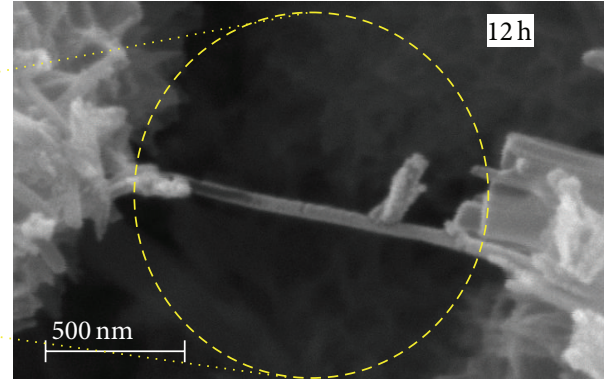

(b) Cement paste with MWCNT-N

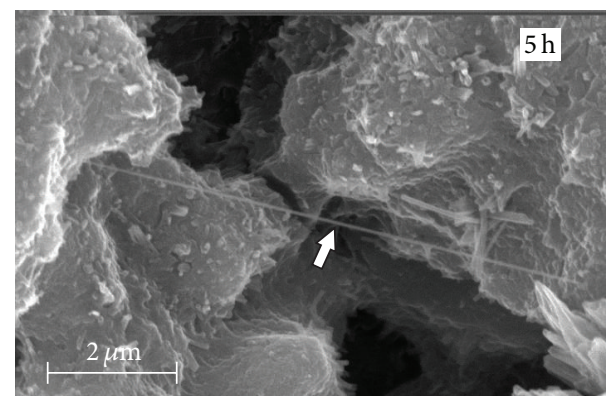

(d) Cement paste with MWCNT-N

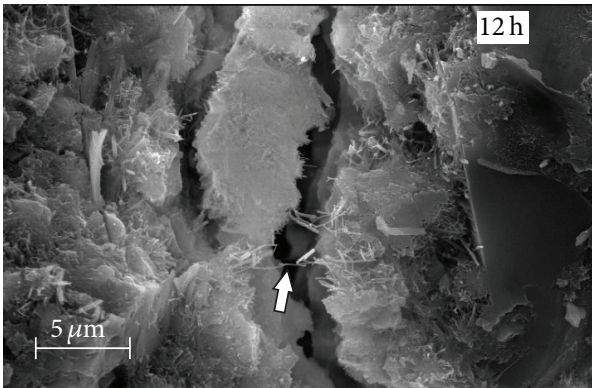

(f) Cement paste with MWCNT-N ${ }_{x}$

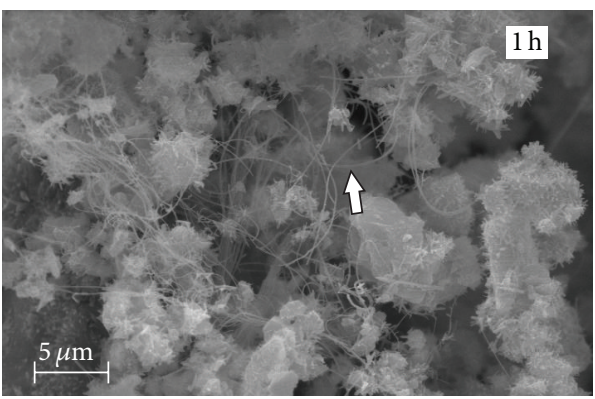

(h) Cement paste with MWCNT-N

FIGURE 8: (a)-(h) SEM images of the hydrated cement paste during the initial hours of the hydration process. The image in (b) corresponds to a close up of (a), showing a carbon nanotube joining two hydrated cement grains (see the enclosed zone). (c) Carbon nanotubes embedded in cement grains. (d) Long carbon nanotube stretched by two cement grains. (e) Cement grains at an early age, growing on a tangle of nanotubes. (h) Cement grains with ettringite bar-shaped structures growing on their surface. The arrows indicate different carbon nanotubes within the cement paste. 


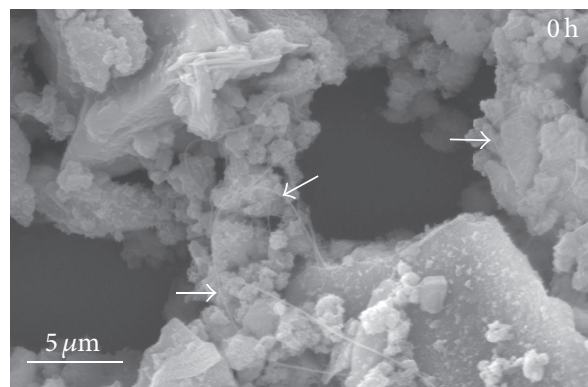

(a) Cement paste with MWCNT-O ${ }_{x}$

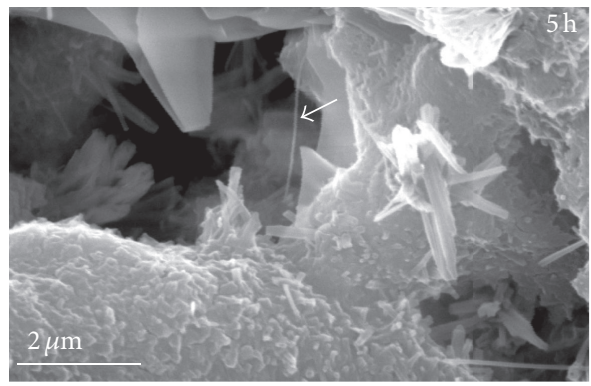

(c) Cement paste with MWCNT-O

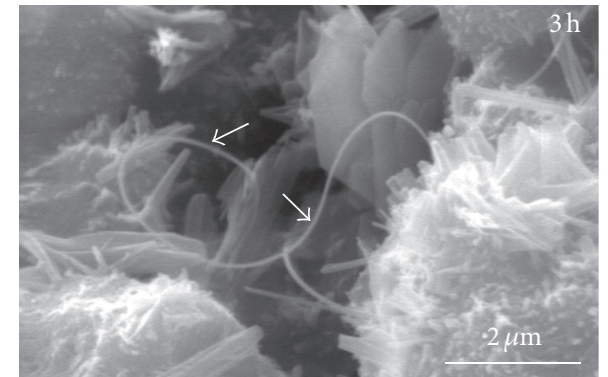

(b) Cement paste with MWCNT-O

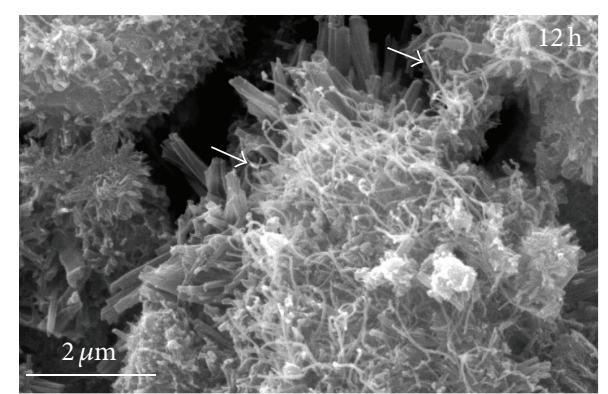

(d) Cement paste with MWCNT-O

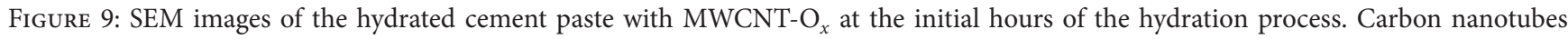
connecting different hydrated cement grains can be appreciated (see the arrows). Ettringite and calcium hydroxide structures are found to be promoted by the hydration process.

ettringite bar-shaped structures start to grow on the grain cement surface with carbon nanotubes inside. Figure 9 shows SEM images of MWCNT-O $\mathrm{O}_{x}$ for different hydration times. At the early age of hydration, long carbon nanotubes interconnecting cement grains are observed (see Figure 9(a)). For one hour of hydration, the ettringite structure, laminar calcium hydroxide clusters, and presence of carbon nanotubes can be appreciated, as depicted in Figure 9(b). An increase of ettringite structures is clearly promoted by a long time of hydration (see Figures 9(c) and 9(d)).

4.3. Carbon Nanotubes Interacting with Calcium Silicate Clusters: DFT Calculations. To elucidate the possible mechanism of the interaction between cement and carbon nanotubes, we simulated a semiconducting zigzag $(10,0)$-SWCNT interacting with a spherical nanoparticle of tricalcium silicate. The complex system containing a nanotube and a nanoparticle exhibits more than 320 atoms, which represents a considerable computational effort. We consider nitrogen-doped and oxygen-functionalized carbon nanotubes. Figure 10 depicts the relaxed structures of a SWCNT-N ${ }_{x}$ and SWCNT-O SW $_{x}$ with calcium silicate particles on the surface. In both types of considered nanotubes, it was observed that $\mathrm{Ca}$ atoms are mainly attached to the nanotube surface. A weak interaction was observed between the calcium silicate clusters and the SWCNT- $\mathrm{N}_{x}$, with the shortest found interatomic distance

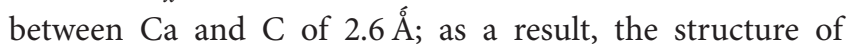
the SWCNT-N $\mathrm{N}_{x}$ is not modified by the presence of a calcium silicate cluster (see Figure 10(a)). More surface activity

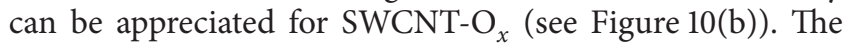

cluster is found to be joined via calcium-oxygen bonds. In addition, calcium atoms were found to remove $\mathrm{OH}$ groups from the carbon nanotube. Note that an improvement in the compressive strength is due to the good connection between the carbon nanotubes and the cementitious matrix; our calculations clearly demonstrated that the SWCNT-O is better attached to a calcium silicate cluster, which is qualitative according to experimental results, as will be shown below. However, more studies in this direction are required.

4.4. Preparation of the Mortars and Measurements of the Compressive Strength. First, the workability properties were analyzed; we observed that the workability was affected by the presence of MWCNTs- $\mathrm{N}_{x}$ and MWCNTs- $\mathrm{O}_{x}$ for a water-cement ratio of 0.5 . This effect on the workability was more pronounced in MWCNT-N $\mathrm{N}_{x}$ most likely because of the lack of functional groups, such as $-\mathrm{COOH}$ and $-\mathrm{OH}$, anchored on the carbon nanotube surface; the absence of functional groups could affect the mortar wettability. In contrast, for a water-cement ratio of $\sim 0.8$, a good workability is achieved with a slump value close to $12 \mathrm{~cm}$. Figure 11 shows the steps performed in the mortar preparation; here, the mechanical properties of the cylindrical specimen are measured by using a universal testing machine with a 5-ton capacity. To investigate the mechanical properties during the hydration process, cylinder specimens $(10 \mathrm{~cm}$ height and $5 \mathrm{~cm}$ diameter) were filled with cement paste based on the samples described above. The dark gray color (right side image in Figure 11(d)) displayed by the cylinder specimens containing carbon nanotubes suggests that these nanotubes are well 

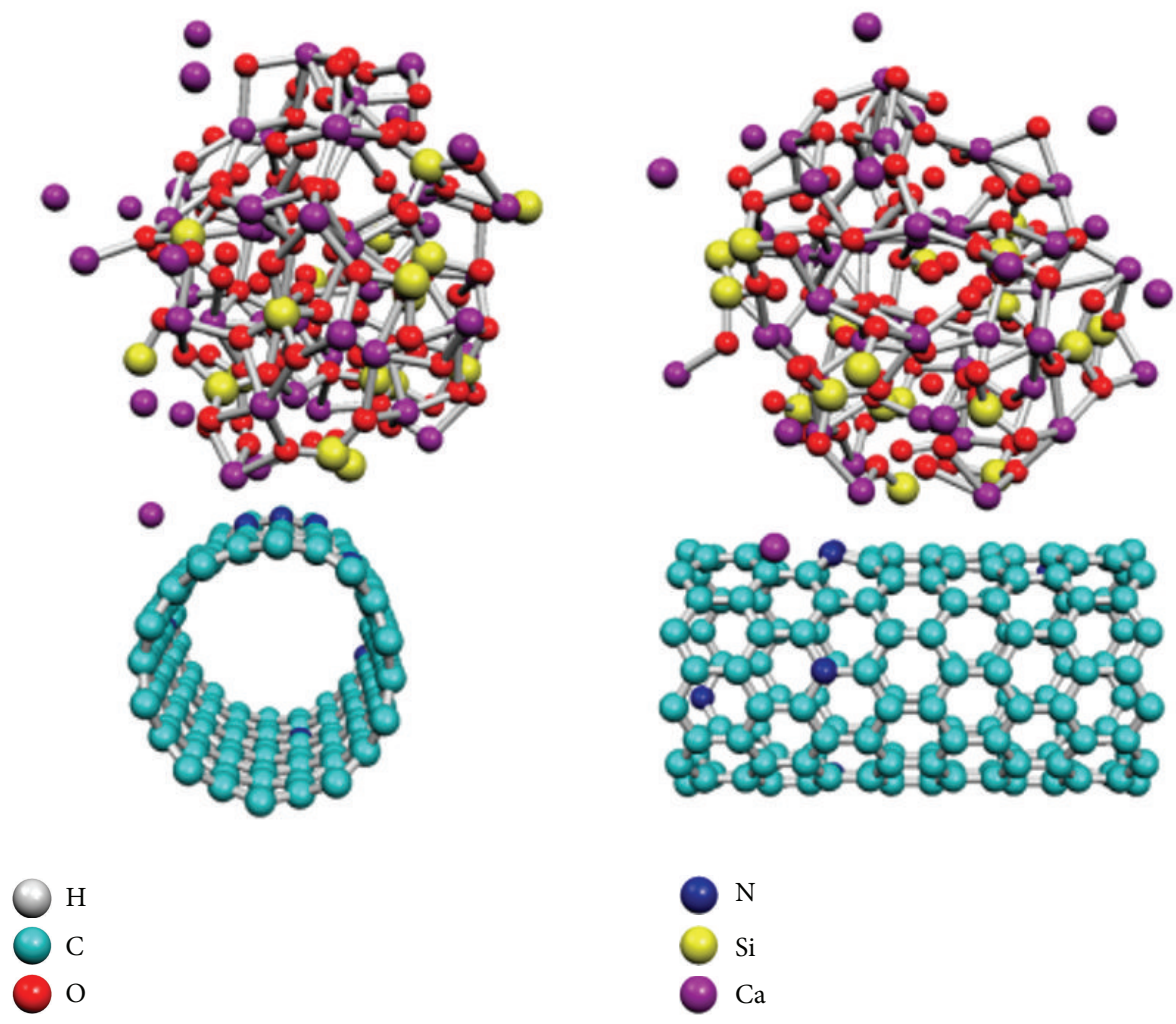

(a) Calcium silicate cluster on SWCNT-N $\mathrm{N}_{x}$
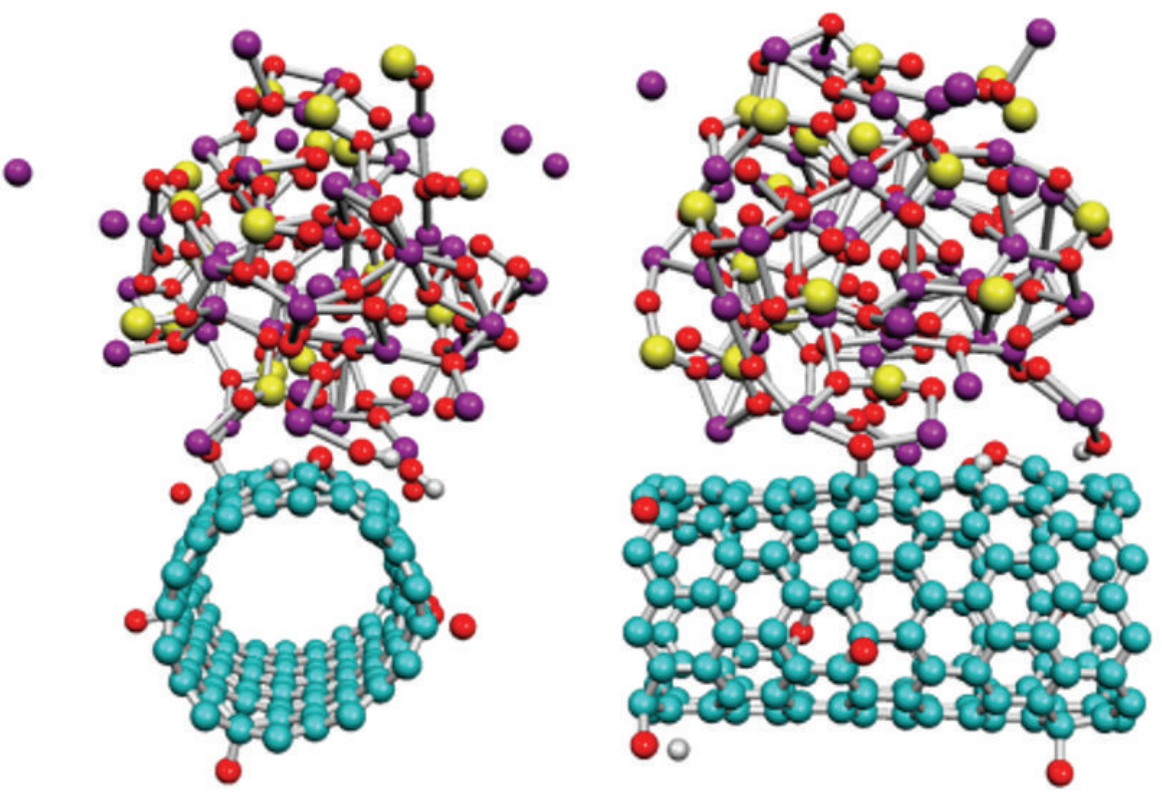
H
○
$\odot \mathrm{C}$
Si
$\mathcal{O} \mathrm{O}$
C $\mathrm{Ca}$

(b) Calcium silicate cluster on SWCNT-O

FIGURE 10: Relaxed structures of a calcium silicate cluster on the surface of carbon nanotubes. Top and side views refer to (a) SWCNT-N SW and (b) SWCNT- $\mathrm{O}_{x}$. In (b), the calcium atoms play an important role in the anchoring of the cluster with the surface of carbon nanotubes. From the transverse section of the SWCNT-O $x$, it is possible to observe an oval section due to the presence of the calcium silicate cluster. 

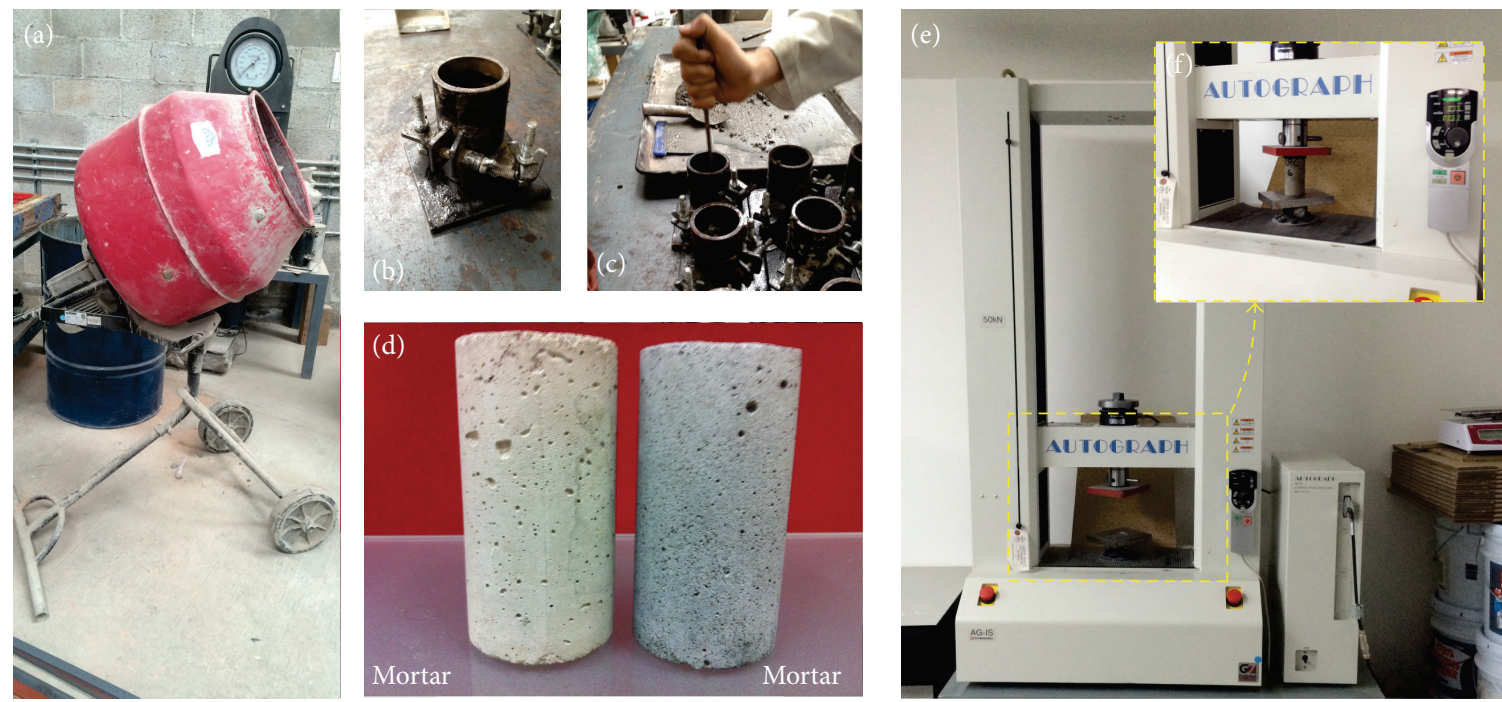

FIGURE 11: (a) Concrete mixing machine of $0.5 \mathrm{~m}^{3}$ capacity, (b) cylindrical metallic mold of $10 \mathrm{~cm}$ in height and $5 \mathrm{~cm}$ in diameter, (c) pouring molds according to the ASTM standard, and (d) cylinders after curing time (without nanotubes (left side) and with carbon nanotubes (right side)). The cylinder concrete with carbon nanotubes exhibits a dark gray color, suggesting that there is a good dispersion of the carbon nanotubes within the mortar matrix. (e) and (f) Universal testing machine (5-ton capacity) used for the compressive strength measurements.

dispersed in the cementitious matrix. The cylindrical samples were subjected to forces perpendicular to the cylinder base (compressive strength).

Figure 12 depicts the compressive strength $\left(\sigma_{c}\right)$ measurement performed during the hydration of mortars containing carbon nanotubes; the results are also compared with the results of conventional mortars (without MWCNT). Note that each point shown in Figure 12 corresponds to an average of five specimens (cylindrical samples). Clearly, the carbon nanotubes play an important role in the compressive strength of the prepared mortars. Regarding mortars without carbon nanotubes, it was observed that cylindrical specimens exhibit values of $\sigma_{c}$ of $\sim 11 \mathrm{MPa}$ at 3 days, reaching values of $\sim 12 \mathrm{MPa}$ at 28 days. A regular strength versus time mortar behavior graph has three important points: in the early ages (0-14 days) it shows a positive slope in behavior, at 14 days regular mortar reaches almost $80 \%$ of design resistance strength, and commonly at 28 days the mortar achieves its resistance design. In Figure 12 we can see a similar behavior in samples without MWCNT in cases with $\mathrm{pH}=7$ (standard used value, neutral water) and $\mathrm{pH}=1$, and also we can see only small differences between both conditions and it means that $\mathrm{pH}$ value is not a factor in concrete behavior only by itself; the values of $\sigma_{c}$ for mortars without carbon nanotubes did not present important changes with water $\mathrm{pH}$.

When MWCNTs- $\mathrm{N}_{x}$ were added to the mortar, it showed two different effects on mortar behavior; they did not appear to improve the mechanical properties when $\mathrm{pH}=1$, probably because of a compatible interaction between nanotube reactive sites and acid water, making a wrap effect on the nanotube surface reducing the possibilities to have interaction between these reactive sites in nanotube with cementitious material while hydration is taking place (see the red circle symbols in Figure 12). Better results were obtained for $\mathrm{pH}=7$ and a sonication time of $1 \mathrm{~h}$ (see Figure 12(c)); probably sonication energy was able to break carbon nanotubes more than enough when time is $2 \mathrm{~h}$, making any link between two cement grains in hydration not possible because of the short nanotube, and this could be the reason to have better results in $\mathrm{pH}=7$ with $1 \mathrm{~h}$ in sonication. Although nitrogen-doped nanotubes have been shown to be able to anchor different species onto their surface [33], the results obtained here indicate that a poor interaction exists between MWCNT- $\mathrm{N}_{x}$ and the cementitious matrix. This finding is in qualitative agreement with the theoretical calculations discussed above. However we can see an important change in the first part of graphs; the slope in mixtures with MWCNT- $\mathrm{N}_{x}$ is greater than reference group, showing an acceleration effect at first hours after mix occurs.

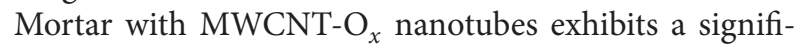
cant improvement in compressive strength for a sonication time of 2 hours (see Figure 12(b)) but only with $\mathrm{pH}=1$ not with $\mathrm{pH}=7$; we can think that, according to publications where functionalization process after carbon nanotube grown using acid substances, acid remains on nanotube surface and it is important to get a better result, and as we observed the sonication process could cause imperfections in nanotube surface increasing reactive sites quantity; this could be the reason why the best result using $\mathrm{MWCNT}-\mathrm{O}_{x}$ is in conditions with $\mathrm{pH}=1$ (acid) and longer time in sonication process to get a good nanotubes dispersion in the mixture. The presence of MWCNT-O ${ }_{x}$ in the mortar promotes an increment in the compressive strength for $\mathrm{pH}=1$, with an observed increment of up to $30 \%$ of the compressive strength with respect to mortars without carbon nanotubes. This fact suggests that, for $\mathrm{pH}=1$ (acid environment), some oxygen functional groups could be attached to the carbon nanotubes, thereby improving the interaction between the cementitious matrix and the surfaces of the carbon nanotubes. 


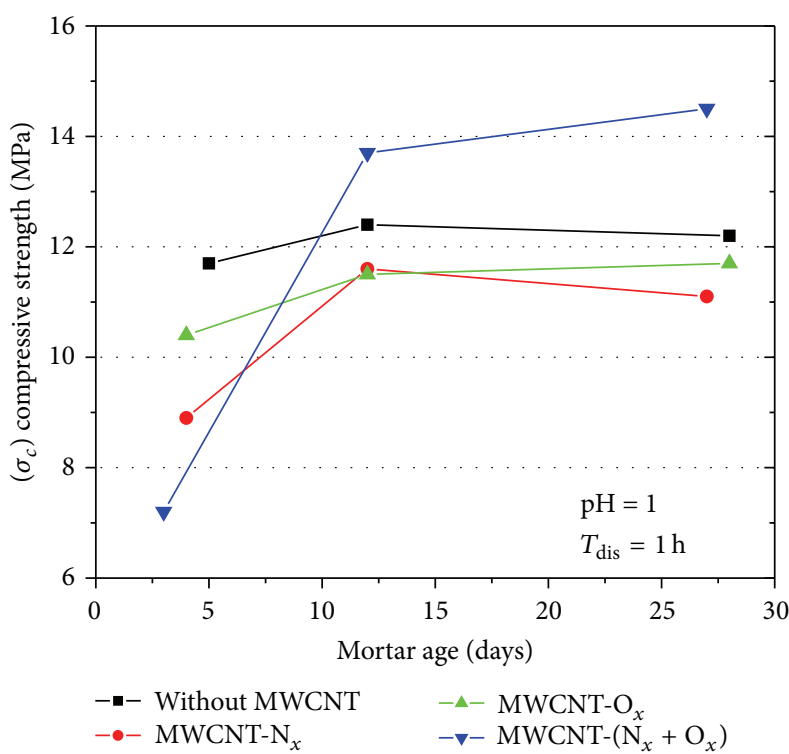

(a)

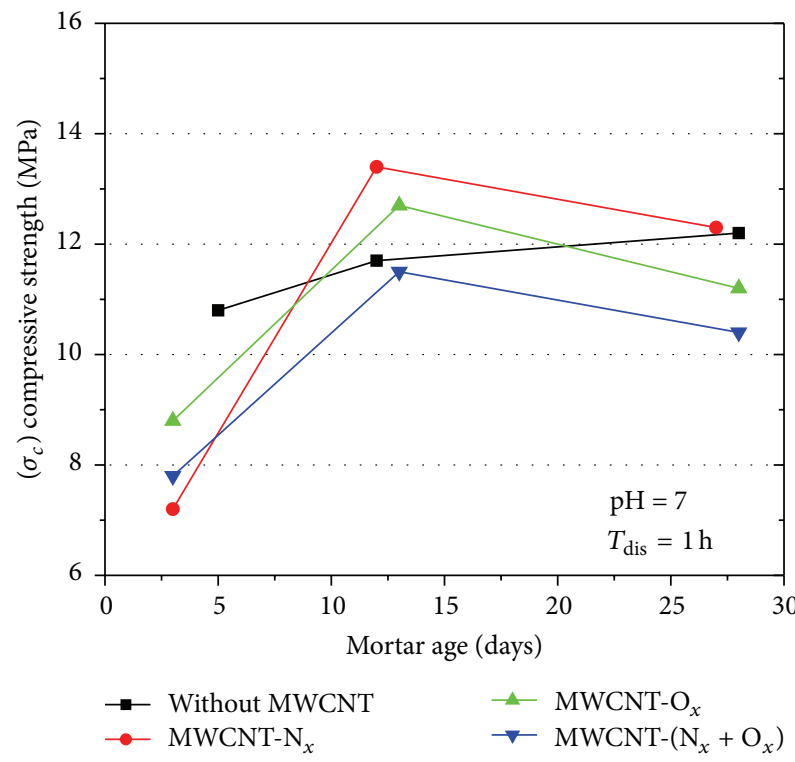

(c)

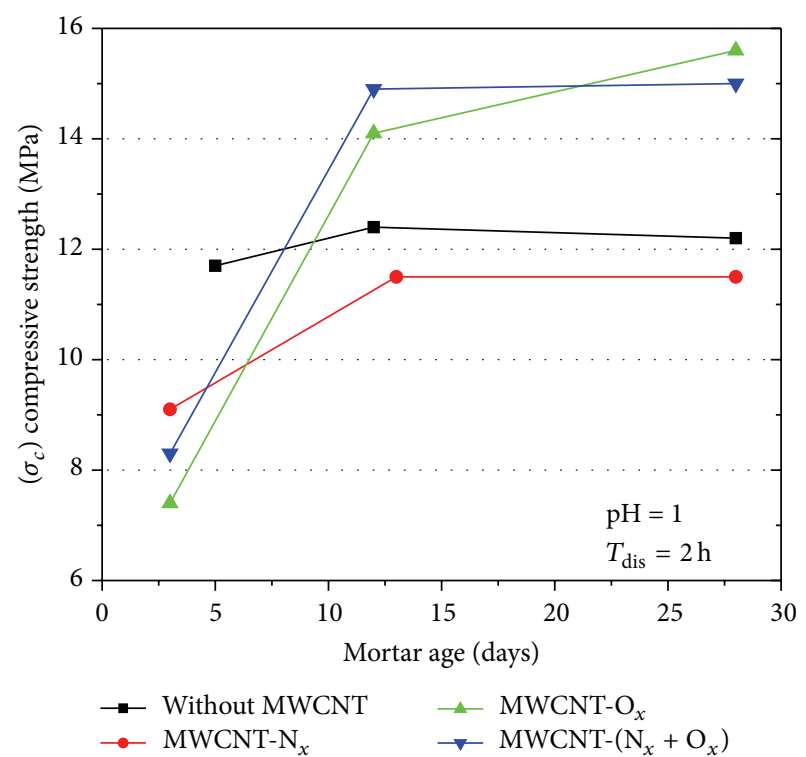

(b)

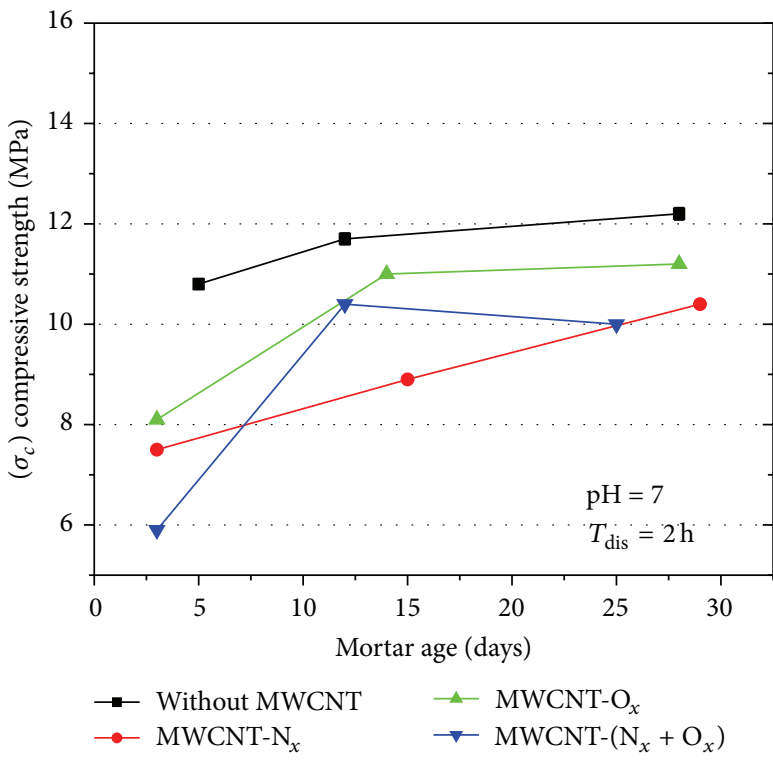

(d)

FIGURE 12: Mechanical resistance (compressive strength) tests performed during the mortar hydration process for mortar containing ordinary Portland cement (OPC), sand, and carbon nanotubes. The water acidity ( $\mathrm{pH}$ value) and the dispersion time $\left(T_{\text {dis }}\right)$ are varied. The results are for mortars without carbon nanotubes, mortars with MWCNT- $\mathrm{N}_{x}$, mortars with MWCNT-O M $_{x}$, and mortars with MWCNT- $\left(\mathrm{N}_{x}+\mathrm{O}_{x}\right)$. All of the tests were performed in cylindrical samples with a height of $10 \mathrm{~cm}$ and a diameter of $5 \mathrm{~cm}$; each of the samples was exposed to forces perpendicular to the cylinder base until the sample broke.

When MWCNT- $\mathrm{O}_{x}$ and MWCNT- $\mathrm{N}_{x}$ are simultaneously mixed with the mortar, the mechanical properties of the mortars are enhanced in circumstances with $\mathrm{pH}=1$, not with $\mathrm{pH}=7$, and it does not look affected by time in dispersion. The effect of mixing carbon nanotubes looks like an algebraic adding (the factors in this addition are not clear yet) of each separated effect of each nanotube type; this could be explored with different quantity ratio and different type of nanostructures in order to understand the overlap effect. This improvement with respect to the other mortars is clearly appreciated for $\mathrm{pH}=1$ (see Figures 12(a) and 12(b)). These results suggest that MWCNT- $\mathrm{O}_{x}$ and MWCNT- $\mathrm{N}_{x}$ interact via nitrogen doping and the different functional groups attached to their surfaces, thus promoting the formation of networks based on interconnected carbon nanotubes; these new structures could play a crucial role in the improvement of the compressive strength.

In Table 2, the mechanical properties of our mortars containing carbon nanotubes are compared with previous results reported by several experimental groups. In Table 2, 
TABLE 2: Comparison of our work with other reports on the mechanical properties of mortars containing multiwalled carbon nanotubes (MWCNTs). The values of the nanotube concentration (\% MWCNTs/cement weight), mechanical properties (flexion, tension, or compression), additional materials or complements (MWCNTs and other materials), and carbon nanotubes treatment are indicated. FUNC (functionalized MWCNTs), US (ultrasonic dispersion), SF (surfactant), SP (superplasticizer), IN SITU (growth of MWCNTs on cement grains).

\begin{tabular}{|c|c|c|c|c|c|}
\hline Reference & $\%$ MWCNTs & $\%$ improvement & Test & Complement & Treatment \\
\hline This work & 0.1 & $30 \%$ & Compression & MWNCT-N $_{x}+$ MWCNT-O $_{x}$ & US \\
\hline Metaxa et al. [1] & 0.8 & - & Compression & MWNCT & $\mathrm{US}+\mathrm{SF}$ \\
\hline Collins et al. [29] & 0.1 & $25 \%$ & Compression & MWNCT & $\mathrm{US}+\mathrm{SP}+\mathrm{CBX}$ \\
\hline Kordkheili et al. [2] & 0.5 & 0 & Compression & MWNCT + nanofibers & $\mathrm{US}+\mathrm{SF}$ \\
\hline Ludvig et al. [3] & 0.3 & $8 \%$ & Compression & MWNCT & IN SITU + SP \\
\hline Morsy et al. [4] & 0.02 & $29 \%$ & Compression & MWNCT + metakaolin & $\mathrm{US}+\mathrm{SP}$ \\
\hline Li et al. [24] & 0.5 & $19 \%$ & Compression & MWNCT FUNC & $\mathrm{US}+\mathrm{SP}$ \\
\hline Musso et al. [22] & 0.5 & $17 \%$ & Compression & MWNCT & $\mathrm{US}+\mathrm{SP}$ \\
\hline Musso et al. [22] & 0.5 & $-80 \%$ & Compression & MWNCT FUNC & $\mathrm{US}+\mathrm{SP}$ \\
\hline Nochaiya and Chaipanich [5] & 1.0 & $17 \%$ & Compression & MWNCT & $\mathrm{US}+\mathrm{SP}$ \\
\hline Torkittikul and Chaipanich [6] & 1.0 & $10 \%$ & Compression & MWNCT & $\mathrm{US}+\mathrm{SP}$ \\
\hline Chaipanich et al. [32] & 1.0 & $10 \%$ & Compression & MWNCT & $\mathrm{US}+\mathrm{SP}$ \\
\hline Nasibulina et al. [8] & - & $100 \%$ & Compression & MWNCT + nanofibers & $\mathrm{US}+\mathrm{SP}$ \\
\hline Wille and Loh [9] & 0.02 & - & Compression & MWNCT + steel fibers & $\mathrm{US}+\mathrm{SP}$ \\
\hline Cwirzen et al. [28] & 0.15 & $50 \%$ & Compression & MWNCT FUNC & $\mathrm{US}+\mathrm{SP}$ \\
\hline Yakovlev et al. [10] & 0.05 & $70 \%$ & Compression & MWNCT & IN SITU + SP \\
\hline Abu Al-Rub et al. [30] & 0.1 & $269 \%$ & Flexion & MWNCT & $\mathrm{US}+\mathrm{SP}$ \\
\hline Tyson et al. [31] & 0.2 & $150 \%$ & Flexion & MWNCT + nanofibers & $\mathrm{US}+\mathrm{SF}$ \\
\hline Hunashyal et al. [7] & 0.5 & $50 \%$ & Tension & MWNCT + fibers & $\mathrm{US}+\mathrm{SP}$ \\
\hline
\end{tabular}

the quantity, treatment, and type of carbon nanotubes are specified. Among the results shown in Table 2, the samples derived by using ultrasonic dispersion in conjunction with a superplasticizer yield an important increment in the efficiency of the mechanical properties, reaching an improvement of up to $100 \%$ for the compressive strength. Our mortars containing MWCNT- $\left(\mathrm{N}_{x}+\mathrm{O}_{x}\right)$ (without superplasticizer) exhibit competitive results compared with the results of the other reports.

\section{Conclusions}

Cement pastes and mortars based on Portland cement reinforced with $M W C N T-N_{x}$ and $M W C N T-O_{x}$ were investigated. The roles of the sonication time and the water $\mathrm{pH}$ of our produced MWCNT-N $\mathrm{N}_{x}$ and $\mathrm{MWCNT}-\mathrm{O}_{x}$ on the cement pastes and concrete were investigated. Here, the carbon nanotubes were sonicated for 1 and 2 hours in water with a $\mathrm{pH}$ of 1 and 7 . The dispersed carbon nanotubes were characterized using SEM and TEM. Cement pastes with and without carbon nanotubes were characterized using SEM at an early age (first hours of hydration). Carbon nanotubes were found to be well incorporated in the cementitious matrix joining different hydrated cement grains. The effects of the dispersion time of the carbon nanotubes and the water $\mathrm{pH}$ on the compressive strength of the mortars were monitored during the hydration process of the mortars; here, the compressive strength was measured on days 3,14 , and 28 . For each day of measurement, the compressive strength was averaged on five cylindrical specimens made of the same mortar. Thus, more than 180 cylindrical specimens were fabricated for the variety of the water $\mathrm{pH}$ and sonication times considered. The compressive strength results revealed that the fabricated concretes exhibit an improved mechanical resistance by approximately $30 \%$ compared with the conventional mortar based only on ordinary Portland cement. Our composite materials exhibit improved efficiency for mortars composed of OPC simultaneously mixed with MWCNT-N ${ }_{x}$ and MWCNT-O $_{x}$ and hydrated with water at a $\mathrm{pH}$ of 1 , reaching up to $15.7 \mathrm{MPa}$ in compressive strength. Furthermore, mortars without carbon nanotubes showed that the compressive strength at an age of 28 days does not depend on the water $\mathrm{pH}$ and carbon nanotube sonication time $\left(\sigma_{c} \sim 12.1 \mathrm{MPa}\right)$. We envision that our composite materials based on OPC and modified carbon nanotubes could be used in building construction as a means to increase the mechanical resistance threshold.

\section{Conflict of Interests}

The authors declare that there is no conflict of interests regarding the publication of this paper.

\section{Acknowledgments}

The authors are grateful to G. J. Labrada-Delgado, B. A. Rivera-Escoto, and K. Gomez for their technical assistance. They are also grateful to E. Muñoz-Sandoval, J. B. Hernández-Zaragoza, D. C. Camacho-Mojica, and Y. I. VegaCantú for fruitful discussions. This work was supported by 
CONACYT Ph.D. scholarships, 267569 (Mauricio MartínezAlanis), CONACYT-México grants: 60218-F1, SEP-CB-20081-106942, and the National Laboratory for Nanoscience and Nanotechnology Research (LINAN).

\section{References}

[1] Z. S. Metaxa, J.-W. T. Seo, M. S. Konsta-Gdoutos, M. C. Hersam, and S. P. Shah, "Highly concentrated carbon nanotube admixture for nano-fiber reinforced cementitious materials," Cement and Concrete Composites, vol. 34, no. 5, pp. 612-617, 2012.

[2] H. Y. Kordkheili, S. Hiziroglu, and M. Farsi, "Some of the physical and mechanical properties of cement composites manufactured from carbon nanotubes and bagasse fiber," Materials \& Design, vol. 33, no. 1, pp. 395-398, 2012.

[3] P. Ludvig, J. M. Calixto, L. O. Ladeira, and I. C. P. Gaspar, "Using converter dust to produce low cost cementitious composites by in situ carbon nanotube and nanofiber synthesis," Materials, vol. 4, no. 3, pp. 575-584, 2011.

[4] M. S. Morsy, S. H. Alsayed, and M. Aqel, "Hybrid effect of carbon nanotube and nano-clay on physico-mechanical properties of cement mortar," Construction and Building Materials, vol. 25, no. 1, pp. 145-149, 2011.

[5] T. Nochaiya and A. Chaipanich, "Behavior of multi-walled carbon nanotubes on the porosity and microstructure of cementbased materials," Applied Surface Science, vol. 257, no. 6, pp. 1941-1945, 2011.

[6] P. Torkittikul and A. Chaipanich, "Bioactivity and mechanical properties of White Portland cement paste with carbon nanotubes," in Proceedings of $3 \mathrm{rd}$ International Nanoelectronics Conference (INEC '10), pp. 838-839, Hong Kong, January 2010.

[7] A. M. Hunashyal, S. V. Tippa, S. S. Quadri, and N. R. Banapurmath, "Experimental investigation on effect of carbon nanotubes and carbon fibres on the behavior of plain cement mortar composite round bars under direct tension," ISRN Nanotechnology, vol. 2011, Article ID 856849, 6 pages, 2011.

[8] L. I. Nasibulina, I. V. Anoshkin, S. D. Shandakov et al., "Direct synthesis of carbon nanofibers on cement particles," Transportation Research Record, vol. 2142, pp. 96-101, 2010.

[9] K. Wille and K. J. Loh, "Nanoengineering ultra-high-performance concrete with multiwalled carbon nanotubes," Transportation Research Record, vol. 2142, pp. 119-126, 2010.

[10] G. Yakovlev, J. Keriene, A. Gailius, and I. Girniené, "Cement based foam concrete reinforced by carbon nanotubes," Materials Science, vol. 12, no. 2, pp. 147-151, 2006.

[11] H. Savastano Jr., P. G. Warden, and R. S. P. Coutts, "Microstructure and mechanical properties of waste fibre-cement composites," Cement \& Concrete Composites, vol. 27, no. 5, pp. 583-592, 2005.

[12] S. H. Alsayed and A. M. Alhozaimy, "Ductility of concrete beams reinforced with FRP bars and steel fibers," Journal of Composite Materials, vol. 33, no. 19, pp. 1792-1806, 1999.

[13] D. D. L. Chung, "Use of polymers for cement-based structural materials," Journal of Materials Science, vol. 39, no. 9, pp. 29732978, 2004.

[14] A. Bilodeau and V. Mohan Malhotra, "High-volume fly ash system: concrete solution for sustainable development," $A C I$ Structural Journal, vol. 97, no. 1, pp. 41-48, 2000.

[15] K. H. Khayat and J. Assaad, "Air-void stability in selfconsolidating concrete," ACI Materials Journal, vol. 99, no. 4, pp. 408-416, 2002.
[16] X. Huang, R. Ranade, W. Ni, and V. C. Li, "On the use of recycled tire rubber to develop low E-modulus ECC for durable concrete repairs," Construction and Building Materials, vol. 46, pp. 134141, 2013.

[17] C. Thomas, J. Setién, J. A. Polanco, I. Lombillo, and A. Cimentada, "Fatigue limit of recycled aggregate concrete," Construction and Building Materials, vol. 52, pp. 146-154, 2014.

[18] F. Sanchez and K. Sobolev, "Nanotechnology in concrete-a review," Construction and Building Materials, vol. 24, no. 11, pp. 2060-2071, 2010.

[19] H. Manzano, A. N. Enyashin, J. S. Dolado, A. Ayuela, J. Frenzel, and G. Seifert, "Do cement nanotubes exist?" Advanced Materials, vol. 24, no. 24, pp. 3239-3245, 2012.

[20] H. Li, H.-G. Xiao, J. Yuan, and J. Ou, "Microstructure of cement mortar with nano-particles," Composites Part B: Engineering, vol. 35, no. 2, pp. 185-189, 2004.

[21] L. Raki, J. Beaudoin, R. Alizadeh, J. Makar, and T. Sato, "Cement and concrete nanoscience and nanotechnology," Materials, vol. 3, no. 2, pp. 918-942, 2010.

[22] S. Musso, J.-M. Tulliani, G. Ferro, and A. Tagliaferro, "Influence of carbon nanotubes structure on the mechanical behavior of cement composites," Composites Science and Technology, vol. 69, no. 11-12, pp. 1985-1990, 2009.

[23] M. M. J. Treacy, T. W. Ebbesen, and J. M. Gibson, "Exceptionally High Young's modules observed for individual carbon nanotubes," Nature, vol. 381, pp. 678-680, 1996.

[24] G. Y. Li, P. M. Wang, and X. Zhao, "Mechanical behavior and microstructure of cement composites incorporating surfacetreated multi-walled carbon nanotubes," Carbon, vol. 43 , no. 6 , pp. 1239-1245, 2005.

[25] G. Y. Li, P. M. Wang, and X. Zhao, "Pressure-sensitive properties and microstructure of carbon nanotube reinforced cement composites," Cement \& Concrete Composites, vol. 29, no. 5, pp. 377-382, 2007.

[26] M. S. Konsta-Gdoutos, Z. S. Metaxa, and S. P. Shah, "Highly dispersed carbon nanotube reinforced cement based materials," Cement and Concrete Research, vol. 40, no. 7, pp. 1052-1059, 2010.

[27] J. M. Makar and G. W. Chan, "Growth of cement hydration products on single-walled carbon nanotubes," Journal of the American Ceramic Society, vol. 92, no. 6, pp. 1303-1310, 2009.

[28] A. Cwirzen, K. Habermehl-Cwirzen, and V. Penttala, "Surface decoration of carbon nanotubes and mechanical properties of cement/carbon nanotube composites," Advances in Cement Research, vol. 20, no. 2, pp. 65-73, 2008.

[29] F. L. Collins, J. Lambert, and W. H. Duan, "The influences of admixtures on the dispersion, workability, and strength of carbon nanotube-OPC paste mixtures," Cement \& Concrete Composites, vol. 34, no. 2, pp. 201-207, 2012.

[30] R. K. Abu Al-Rub, A. I. Ashour, and B. M. Tyson, "On the aspect ratio effect of multi-walled carbon nanotube reinforcements on the mechanical properties of cementitious nanocomposites," Construction and Building Materials, vol. 35, pp. 647-655, 2012.

[31] B. M. Tyson, R. K. Abu Al-Rub, A. Yazdanbakhsh, and Z. Grasley, "Carbon nanotubes and carbon nanofibers for enhancing the mechanical properties of nanocomposite cementitious materials," Journal of Materials in Civil Engineering, vol. 23, no. 7, pp. 1028-1035, 2011.

[32] A. Chaipanich, T. Nochaiya, W. Wongkeo, and P. Torkittikul, "Compressive strength and microstructure of carbon nanotubes-fly ash cement composites," Materials Science and Engineering: A, vol. 527, no. 4-5, pp. 1063-1067, 2010. 
[33] M. Terrones, A. G. S. Filho, and A. M. Rao, "Doped carbon nanotubes: synthesis, characterization and applications," in Carbon Nanotubes: Advanced Topics in the Synthesis, Structure, Properties and Applications, A. Jorio, G. Dresselhaus, and M. S. Dresselhaus, Eds., Topics in Applied Physics, pp. 531-566, Springer, 2008.

[34] R. Czerw, M. Terrones, J.-C. Charlier et al., "Identification of electron donor states in N-doped carbon nanotubes," Nano Letters, vol. 1, no. 9, pp. 457-460, 2001.

[35] A. Botello-Méndez, J. Campos-Delgado, A. Morelos-Gómez et al., "Controlling the dimensions, reactivity and crystallinity of multiwalled carbon nanotubes using low ethanol concentrations," Chemical Physics Letters, vol. 453, no. 1-3, pp. 55-61, 2008.

[36] P. Hohenberg and W. Kohn, "Inhomogeneous electron gas," Physical Review, vol. 136, article B864, 1964.

[37] W. Kohn and L. J. Sham, "Self-consistent equations including exchange and correlation effects," Physical Review Letters, vol. 140, pp. A1133-A1138, 1965.

[38] J. P. Perdew, A. Ruzsinszky, G. I. Csonka et al., "Restoring the density-gradient expansion for exchange in solids and surfaces," Physical Review Letters, vol. 100, no. 13, Article ID 136406, 2008.

[39] J. M. Soler, E. Artacho, J. D. Gale et al., "The SIESTA method for ab initio order- $N$ materials simulation," Journal of Physics Condensed Matter, vol. 14, no. 11, pp. 2745-2779, 2002.

[40] J. Junquera, Ó. Paz, D. Sánchez-Portal, and E. Artacho, "Numerical atomic orbitals for linear-scaling calculations," Physical Review B-Condensed Matter and Materials Physics, vol. 64, no. 23, Article ID 235111, pp. 2351111-2351119, 2001.

[41] N. Troullier and J. L. Martins, "Efficient pseudopotentials for plane-wave calculations," Physical Review B, vol. 43, no. 3, pp. 1993-2006, 1991.

[42] L. Kleinman and D. M. Bylander, "Efficacious form for model pseudopotentials," Physical Review Letters, vol. 48, no. 20, pp. 1425-1428, 1982.

[43] S. J. Chen, B. Zou, F. Collins, X. L. Zhao, M. Majumber, and W. H. Duan, "Predicting the influence of ultrasonication energy on the reinforcing efficiency of carbon nanotubes," Carbon, vol. 77, pp. 1-10, 2014. 

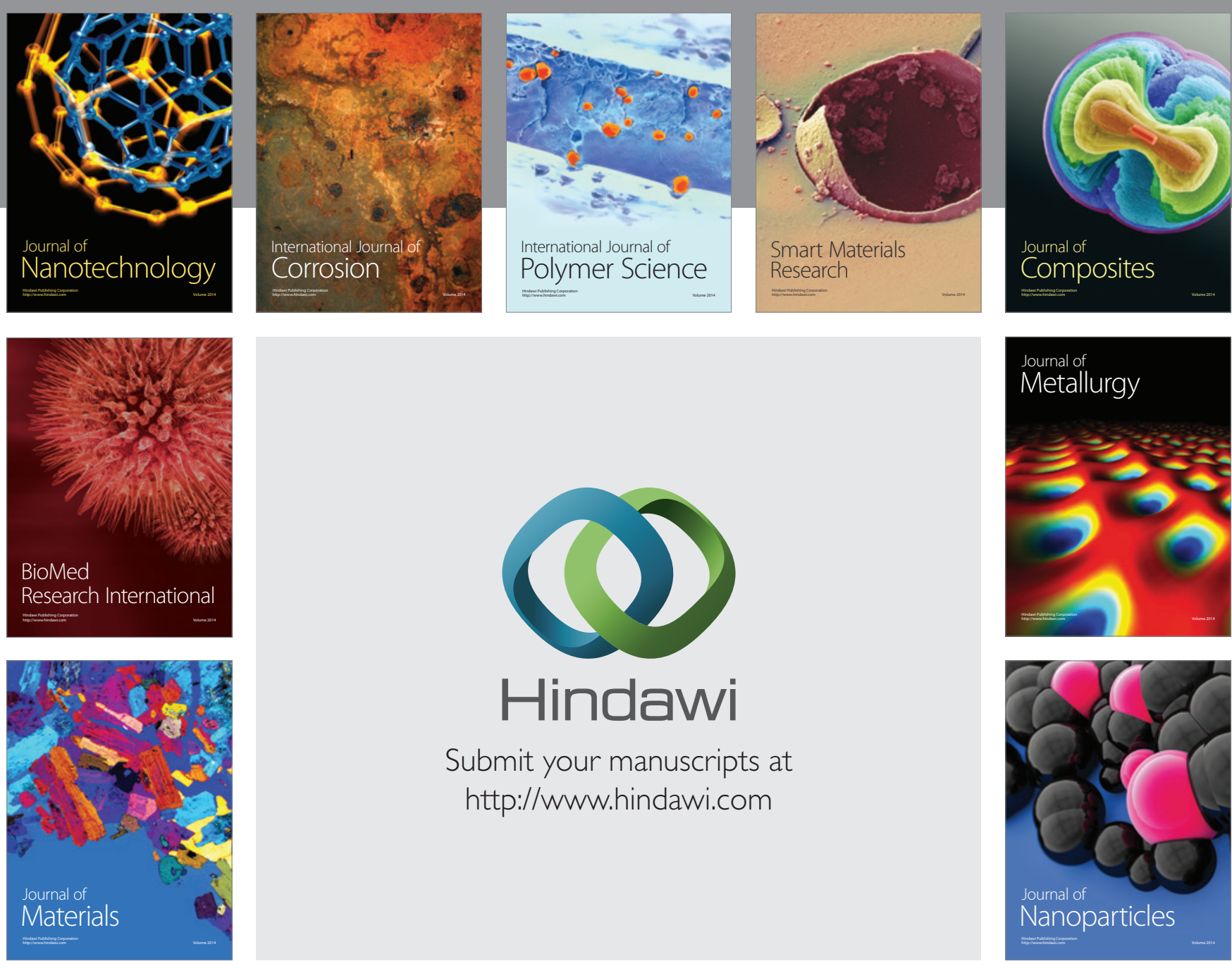

\section{Hindawi}

Submit your manuscripts at

http://www.hindawi.com

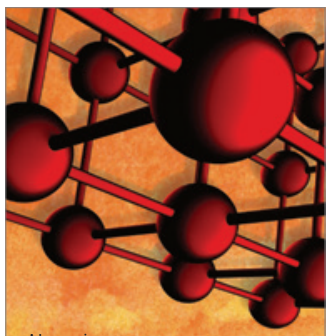

Materials Science and Engineering
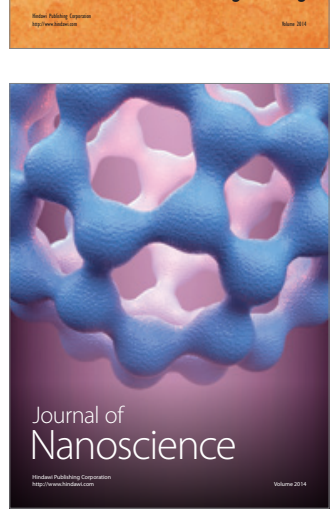
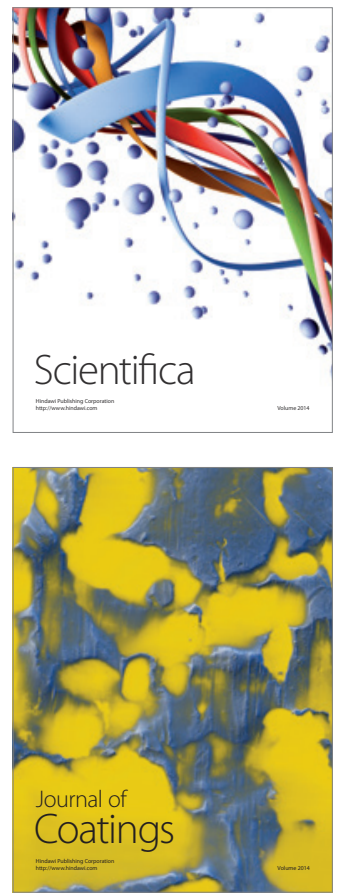
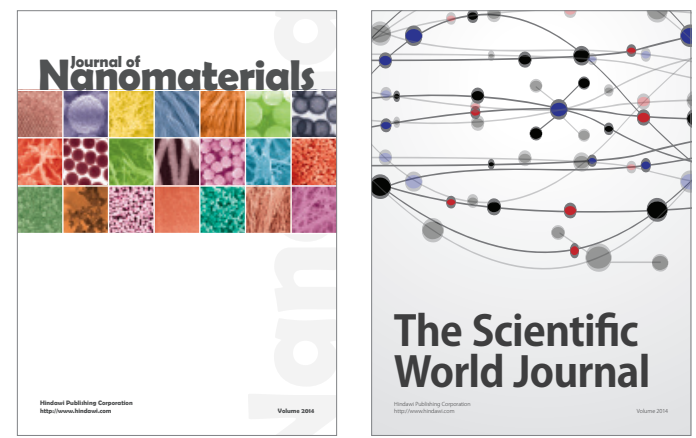

The Scientific World Journal
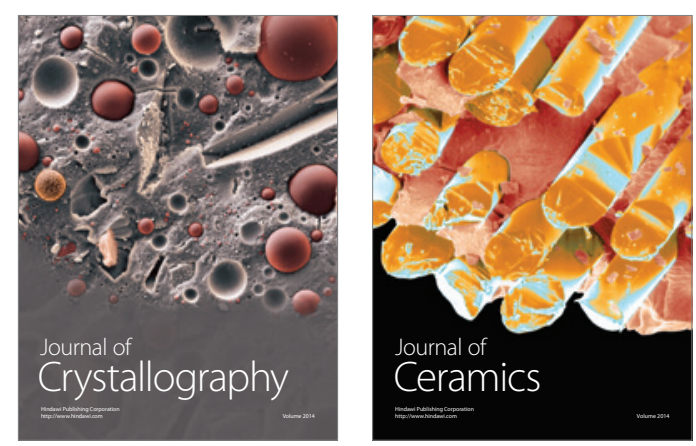
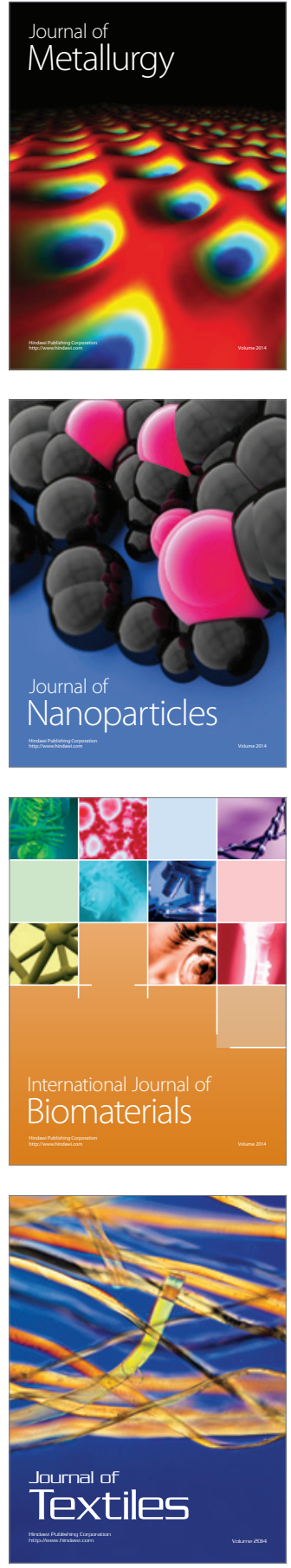